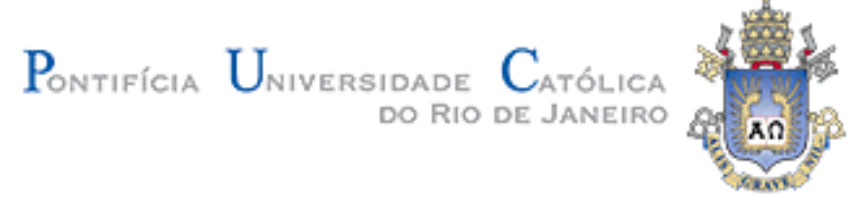

Theiza Conte Paiva

\begin{abstract}
Uma Análise Fenomenográfica Sobre Compartilhamento de Competências nas Rotinas de Inovação
\end{abstract}

Dissertação de Mestrado

Dissertação apresentada ao Programa de PósGraduação em Administração de Empresas da PUCRio como requisito como requisito parcial para obtenção do grau de Mestre em Administração de Empresas.

Orientador: Profa. Sandra Regina da Rocha Pinto

Rio de Janeiro

Abril 2015 


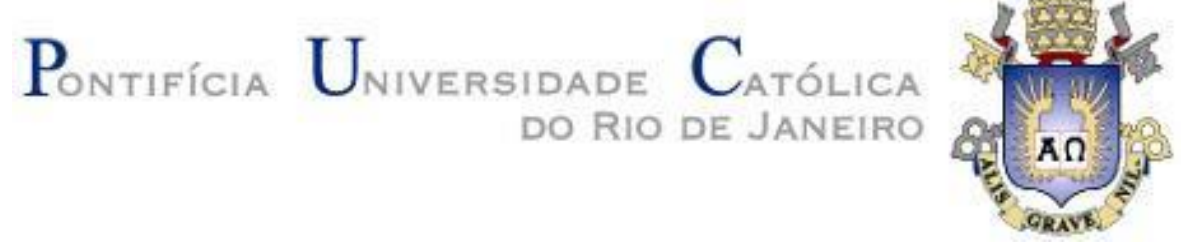

Theiza Conte Paiva

\title{
UMA ANÁLISE FENOMENOGRÁFICA SOBRE COMPARTILHAMENTO DE COMPETÊNCIAS NAS ROTINAS DE INOVAÇÃO
}

Dissertação apresentada como requisito parcial para obtenção do grau de Mestre pelo Programa de Pós-Graduação em Administração de Empresas da PUC-Rio. Aprovada pela Comissão Examinadora abaixo assinada.

\author{
Profa. Sandra Regina da Rocha Pinto \\ Orientadora \\ Departamento de Administração - PUC-Rio
}

Profa. Andrea Cherman Departamento de Administração - PUC-Rio

Prof. Carlos Teixeira

Parsons

Prof ${ }^{\text {a. }}$ Mônica Herz Vice-Decana de Pós-Graduação do CCS - PUC-Rio

Rio de Janeiro, 9 de abril de 2015 
Todos os direitos reservados. É proibida a reprodução total ou parcial do trabalho sem a autorização da universidade, do autor e do orientador.

\section{Theiza Conte Paiva}

Graduou-se em Administração de Empresas pela UFRJ. Cursou Pós-Graduação em Marketing Estratégico pela FGV, em Gerenciamento de Recursos Humanos com foco em Endomarketing pela UFRJ. Em 2006 cursou o Programa de Extensão em Branding em Kellog School University of Chicago e, em 2012, o Executive Program de Warthon University Strategic Thinking and Management for Competitive Advantage.

Ficha Catalográfica

Paiva, Theiza Conte

Uma análise fenomenográfica sobre compartilhamento de competências nas rotinas de inovação / Theiza Conte Paiva ; orientador: Sandra Regina da Rocha Pinto. - 2015.

75 f. : il. ; $30 \mathrm{~cm}$

Dissertação (mestrado)-Pontifícia Universidade Católica do Rio de Janeiro, Departamento de Administração, 2015.

Inclui bibliografia

1. Administração - Teses. 2. Competência coletiva. 3. Compartilhamento de competências. 4. Inovação. 5. Soluções inovadoras. I. Pinto, Sandra Regina da Rocha. II. Pontifícia Universidade Católica 
Para Lara, minha filha, fonte de luz, de inspiração, de alegria e de amor.

Para Celia, minha mãe, fonte eterna de coragem, de delicadeza, de amizade e de amor.

Para Beto, meu pai, fonte de verdade, de leveza, de amizade e de amor. 


\section{Agradecimentos}

A Deus, Nosso Pai, que sempre está ao meu lado.

À Sarah, minha amiga de fé.

À minha família de alma e de sangue: Suely, Maria Lúcia, Nelson, Yana, Maria Clara e Ygor.

Aos professores que entraram em sala de aula para me relembrar que aprender é um dos maiores prazeres da vida: Alessandra Costa, Angela da Rocha, Diana de Macedo Soares, Jorge Carneiro, Jorge Ferreira, Luis Pessoa, Luiz Felipe e Paulo Cesar Motta.

Aos meus colegas de turma que deram um significado especial a este aprendizado.

À Professora Sandra Regina Rocha-Pinto pela paciência e pelo saber-fazer.

Ao Professor Carlos Teixeira que me conduziu silenciosamente à decisão de fazer este estudo.

À Professora Andréa Cherman que apresentou um caminho para esta pesquisa.

A todos os entrevistados desse estudo que se disponibilizaram prontamente com enorme carinho e atenção.

À Teresa Campos, ao Gilson e ao Sergio Terra que todos os dias me relembraram que dependemos de muitos para realizar nossos sonhos.

E, aos meus grandes amigos e aos meus queridos familiares, que me acompanham, real e virtualmente, com tanto amor ao longo da vida 


\section{Resumo}

Paiva, Theiza Conte; Pinto, Sandra Regina da Rocha. Uma Análise Fenomenográfica Sobre Compartilhamento De Competências Nas Rotinas De Inovação. Rio de Janeiro, 2015. 75p. Dissertação de Mestrado, Pontifícia Universidade Católica do Rio de Janeiro.

O campo da Gestão da Inovação tem buscado entender e descrever como ocorre o processo de geração de propostas de soluções evolutivas, de melhoria ou inovadoras dentro das organizações. Este trabalho busca entender como a dinâmica de trabalho de grupos de indivíduos ocorre, através das atividades formais ou informais ligadas à busca de solução inovadora de problemas, nas perspectivas do compartilhamento de competências individuais e da construção da competência coletiva. A pesquisa fenomenográfica foi realizada entre 01 de setembro e 22 de outubro de 2014 por meio de 20 entrevistas presenciais, semiestruturadas, com gestores e profissionais sêniores de 10 organizações. A análise dos conceitos das vivências e percepções destes indivíduos acerca do fenômeno de compartilhar competência no âmbito das rotinas de inovação gerou a identificação de três categorias de descrição (Tabela 2): Criação de Competência Coletiva, Transformação do Fazer e Construção de Padrão de Pensamento, que foram descritas em cinco dimensões explicativas: Conceito de Compartilhamento de Competência, Perspectiva de Competência Individual, Perspectiva de Competência Coletiva, Dinâmica das Rotinas Organizacionais e Contexto de Processos Inovadores. Estas categorias emergiram das experiências relatadas pelos entrevistados em grau de abrangência crescente e de acordo com os respectivos entendimentos sobre o processo de trabalho de uma equipe que busca soluções inovadoras: uma dinâmica de construção conjunta que é realizada por um grupo de indivíduos resultado de um pensamento coletivo e continuado.

\section{Palavras-chave}

Competência coletiva; compartilhamento de competências; inovação; soluções inovadoras. 


\section{Abstract}

Paiva, Theiza Conte; Pinto, Sandra Regina da Rocha. (Advisor). Phenomenographic Analysis on Sharing Competences in Innovation Routines. Rio de Janeiro, 2015. 75p. MSc. Dissertation - Departamento de Administração, Pontifícia Universidade Católica do Rio de Janeiro.

The field of Innovation Management has sought to understand and describe how the process of evolutive, improvement and innovative solutions proposals occur inside organizations. This works seeks to understand how the work dynamic of groups of individuals occur through formal or informal activities linked to the search of innovative problem solving, in both sharing individual competencies and constructing collective competencies perspectives. The phenomenographic research was done between September 1st, 2014 and October 22nd, 2014 having 20 interviews, semistructured, with managers and senior professionals of 10 organizations. The analysis of the experience concept and the perceptions of these individuals about the competence sharing phenomenon in the innovation routine scope identified three description categories (Table 2): Collective Competence Creation, Transformation of Doing and Thought Pattern Creation, which were described into five explicative dimensions: Competence Sharing Concept, Individual Competence Perspective, Collective Competence Perspective, Dynamic of Organizational Routines, Innovative Processes Context. These categories emerged from experiences reported by the interviewees in increasing degrees of coverage and also according with respective understandings about work processes in a team looking for innovative solutions: a joint construction dynamic performed by a group of individuals resulted from collective and continuous thought.

\section{Keywords}

Collective competencies; competence sharing; innovation; innovative solutions. 


\section{Sumário}

1 Introdução 12

$\begin{array}{ll}\text { 1.1 Problema e Objetivos do Estudo } & 14\end{array}$

1.2 Relevância do Estudo 15

$\begin{array}{ll}1.3 \text { Delimitação do Estudo } & 16\end{array}$

2 Referencial Teórico $\quad 17$

2.1 Compartilhamento do Conhecimento e Gestão da Inovação 17

$\begin{array}{ll}2.2 \text { Competências Coletivas } & 21\end{array}$

$\begin{array}{ll}\text { 2.2.1 Conceitos e definições } & 21\end{array}$

2.2.2 Configuração das Competências Coletivas 23

2.2.3 Gestão das Competências Coletivas 26

$\begin{array}{ll}2.3 \text { Rotinas Organizacionais } & 28\end{array}$

3 Metodologia 32

3.1 Concepção e estratégia da pesquisa 32

3.2 Método de Pesquisa 33

3.2.1 A escolha método 33

3.3.2 Características do Método 33

3.2.3 As perspectivas de segunda ordem: experimentar o objeto 34

3.2.4 Desafio: descrever as variações das experiências 35

$\begin{array}{ll}\text { 3.2.5 Limitações do Método } & 37\end{array}$

$\begin{array}{ll}\text { 3.2.6 Amostra Intencional } & 37\end{array}$

3.2.7 Coleta dos dados e as entrevistas 38

3.2.8 Análise e interpretação dos dados 39

4 Análise e interpretação dos dados 41 
4.1 As concepções dos indivíduos em relação ao compartilhamento de competência para a busca de soluções de problemas

4.1.1 Compartilhamento de Competências nas Rotinas de Inovação como Criação de Competências Coletivas

4.1.2 Compartilhamento de Competências nas Rotinas de Inovação como Transformação do Fazer

4.1.3 Compartilhamento de Competências nas Rotinas de Inovação como Construção de Padrão de Pensamento

4.2 A Correlação das Concepções dos Indivíduos em relação ao compartilhamento de competência para a busca de soluções de problemas

5 Considerações Finais

5 Referências Bibliográficas

Apêndices

73

Apêndice 1 Roteiro Semiestruturado 
Lista de Tabelas

Tabela 1 - Perfil dos entrevistados

38

Tabela 2 - Espaço de Resultado para as concepções sobre

Compartilhamento de Competências em Rotinas de Inovação

62

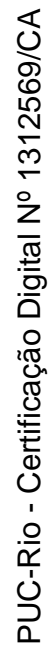




\section{Lista de Figuras}

Figura 1 - Mapa do Espaço de Resultado para as concepções sobre Compartilhamento de Competências em Rotinas de Inovação. 


\section{Introdução}

Em um mundo onde os mercados, os produtos e serviços, as tecnologias, os competidores, os governos e até mesmo sociedades inteiras mudam muito rapidamente, a inovação contínua e o conhecimento, que proporciona esta inovação, passam a representar fontes importantes de vantagem competitiva sustentável para as organizações (NONAKA, TOYAMA e BYOSIÈRE, 2001).

Essas constantes mudanças têm pressionado as organizações a buscarem combinações diferenciadas de suas competências como forma de potencializar vantagem competitiva ou mesmo para assegurar sua sobrevivência (Bittencour e Klein, 2012)

Segundo Drucker (apud BONINI e SBRAGIA, 2011), o que diferencia a inovação, da invenção e da descoberta, é o fato de ir além da aquisição do conhecimento, gerando um novo desempenho econômico para uma empresa. Assim, inovação está relacionada à geração de resultados para a organização, seus clientes e seus outros públicos-alvo.

Sob esta perspectiva, a inovação pode assumir uma importância mais ampla, mesmo que de menor visibilidade, que vai além do desenvolvimento de novos produtos e serviços. O processo de inovação pode resultar em diminuição de custos de produção, logística e marketing, como também de melhoria de performance da cadeia produtiva (THAMHAIN, 2003) e dos próprios processos realizados pelos indivíduos e equipes de trabalho durante suas atuações profissionais. Estes resultados positivos podem não ser necessariamente tangibilizados pelo consumidor final, mas são fundamentais para a obtenção de vantagens competitivas.

O processo que envolve a geração de ideias inovadoras parece ser complexo e de difícil controle e gestão. Muitas organizações continuam a lidar com o assunto como se fosse uma "caixa preta" (AWAZU, DESOUZA, DOMBROWSKI, BALOH, PAPAPGARI JAH e KIM, 2009): somente por acaso 
algumas ideias são consideradas e por sorte investigadas, desenvolvidas e comercializadas. Desta forma, inovação ainda pode ser comumente percebida como o resultado de um processo de ruptura normalmente inesperado, e não como uma atividade fundamental na gestão do negócio: que pode ter seus padrões, regras, processos e gerenciamento definidos e institucionalizados.

A cultura e a gestão organizacionais influenciam significativamente a existência de um ambiente inovador. Segundo Lam (2004), as empresas mecanicistas são adaptadas às condições estáveis e, consequentemente, menos propensas a uma cultura que promova uma gestão para inovação. Já as empresas denominadas orgânicas são mais fluidas nos seus arranjos organizacionais, se adaptando às situações de constantes mudanças e mais propensas a uma gestão inovadora. E, na visão de Teece (2002), as empresas podem ter abordagens para inovação autônomas ou sistêmicas. Autônomas são as que geram condições necessárias para que as inovações possam ser desenvolvidas sem depender de outras iniciativas inovadoras dentro da organização, e sistêmicas, as que são codependentes de outras iniciativas inovadoras para serem implementadas.

A forma como indivíduos e grupos atuam, interagem e buscam soluções inovadoras dentro destes diversos contextos e níveis de institucionalização da inovação nas organizações - com suas peculiares culturas, seus modelos de gestão e suas estratégias de negócios - é o principal objetivo deste estudo.

Souza (2013) apresenta a inovação em sua dimensão social que envolve: a introdução de novos processos, produtos e serviços no contexto social; sua aceitação por parte dos indivíduos integrantes de tal contexto social; o reconhecimento do caráter útil que tais novidades proporcionam; e iniciativas de gestão dessa implementação.

No âmbito das Competências Organizacionais, estudos e conceitos sobre Competências Individuais e Coletivas abordam o compartilhamento e integração de saberes e saberes-fazer como uma abordagem a ser considerada nas rotinas/processos de busca de soluções inovadoras.

Retour, Picq, Defélix e Ruas (2011) apresentam definições de Competência Coletiva de diferentes autores, quando pode-se observar a presença frequente das perspectivas de compartilhamento e de interação entre os indivíduos 
de seus saberes e saberes-fazer para gerarem resultados diferentes dos originais, como também novos conhecimentos e competências. Como exemplo, Le Boterf (2003) destaca o caso da Tefal, uma empresa que desenvolveu um modelo de crescimento pela inovação, por promover práticas coletivas de capitalização dos saberes-fazer e das experiências. Segundo o autor, "os processos de atividades se aperfeiçoam sob o efeito da aprendizagem e da inovação"

Inovação não é mais resultado de gênios individuais, mas de esforços envolvendo times de pessoas interagindo em ambientes complexos, intricados e até mesmo caóticos. O processo de inovação decorre da forma de atuar destes grupos inseridos em contextos organizacionais mais ou menos propensos à inovação, sendo válido investigar com maior atenção a vivência individual e coletiva destes grupos na busca de soluções inovadoras (THAMHAIN, 2003).

\section{1 \\ Problema e Objetivos do Estudo}

Apesar das pesquisas em torno dos processos de gestão que levam à inovação apresentarem importantes análises e achados sobre a atuação dos times e equipes nos processos e rotinas de busca de soluções inovadoras, ainda existe a necessidade de entendimento da importância da interação do conhecimento e habilidades individuais no âmbito de práticas coletivas (RUAS, SILVA, BECKER e COMINI, 2013).

Este trabalho se propõe a investigar a relação entre os conceitos de Competências Coletivas e as Rotinas/processos de Inovação dentro das organizações. Com este foco, o estudo irá buscar como o compartilhamento dos saberes e saberes-fazer (conhecimentos tácitos e explícitos) de profissionais com diferentes talentos, formações e experiências individuais, influenciam e contribuem para o processo de desenvolvimento de soluções inovadoras.

O conceito de Competências Coletivas é mencionado no referencial teórico deste estudo, porém a importância de seus elementos constitutivos nas rotinas/processos que envolvem as/os rotinas/processos de busca de soluções inovadoras, ainda é pouco explorada. Diante disto, se estabelece a seguinte pergunta de pesquisa: 
1. Como os indivíduos vivenciam (ou experimentam) o compartilhamento das competências individuais nas rotinas/processos de busca de solução inovadoras e percebem a integração destas competências individuais no âmbito coletivo dos grupos ou equipes?

Os objetivos secundários apresentados a seguir contribuíram para a resposta ao problema acima proposto:

1. Levantar até que ponto os indivíduos consideram relevante o compartilhamento e a integração dos conhecimentos (ou saberes) individuais nas rotinas/processos de busca de solução inovadoras.

2. Levantar até que ponto os indivíduos consideram a participação de indivíduos com diferentes saberes importante para que ocorra o compartilhamento de conhecimentos (ou saberes) individuais nas rotinas/processos de busca de solução inovadoras.

3. Identificar quais as características - individuais e coletivas - que os indivíduos percebem como relevantes para o compartilhamento das competências nas rotinas/processos de busca de solução inovadoras.

\section{2 \\ Relevância do Estudo}

Inovação tem sido considerada como um dos principais direcionamentos estratégicos das organizações, gerando vantagem competitiva e contribuindo para uma posição de liderança sustentável das organizações (BONINI e SBRAGIA, 2011).

Entender como os processos que levam à inovação são influenciados pelo compartilhamento de competências pode contribuir para que a gestão de processos de inovação se torne mais eficaz e, consequentemente, traga resultados com maior valor agregado aos negócios.

Além da importância do compartilhamento de competências em grupos de trabalho que buscam soluções inovadoras de soluções, também parece ser relevante buscar o entendimento da dinâmica das rotinas/processos dos grupos: de interagir para compartilhar conhecimento, sua forma de realizar atividades e 
tarefas comuns e seus pensamentos durante este processo de busca por novas soluções em conjunto com outros indivíduos que visam um mesmo objetivo para a organização.

\section{3}

\section{Delimitação do Estudo}

Apesar da existência de diferentes conceitos construídos por autores dedicados ao tema, este estudo considera que Competências Coletivas são:

"vistas como o resultado da interação entre competências individuais, com base nos sentidos compartilhados e nos processos de interação. Está, portanto, voltada à capacidade que um grupo de pessoa tem para realizar atividades e tarefas que não poderiam ser realizadas individualmente. São desse modo, as competências da organização e também as competências dos grupos de trabalho (equipes, áreas e/ou funções)" (Silva, 2012).

Este trabalho busca analisar e entender a atuação, importância e contribuição de equipes multidisciplinares no processo de busca de soluções inovadoras, aqui caracterizadas como aquelas soluções que trouxeram melhorias, resultados ou benefícios internos e externos para a organização, além de terem gerado novos conhecimentos.

Além do entendimento e percepção dos conceitos de competência e de solução inovadora por parte dos profissionais entrevistados, será explorado o fenômeno da inter-relação de ambos nas rotinas de grupos de trabalho que buscam soluções de melhoria, evolução e/ou diferenciação na perspectiva das áreas organizacionais onde os participantes exercem suas atividades profissionais.

Outra delimitação diz respeito aos profissionais, a seleção de sujeitos. O grupo de entrevistados é composto por gestores e profissionais sêniores da área de Marketing e Comunicação de Marketing de 10 empresas de diferentes portes (pequeno, médio e grande) de diferentes segmentos de mercado. 


\section{2 \\ Referencial Teórico}

O presente estudo busca analisar a relação entre o processo de compartilhamento de competências nas rotinas que buscam soluções inovadoras, considerando que a diversidade de saberes e saberes-fazer (teóricos e práticos) é importante subsídio para gerar soluções inovadoras.

O presente capítulo apresenta três referenciais teóricos que fundamentaram este estudo: Competências Coletivas, Inovação e Rotinas Organizacionais. A Competência Coletiva é abordada como uma construção de novos conhecimentos por parte de um grupo de trabalho que utiliza este saber no processo de criação de soluções. O segundo referencial apresenta a Inovação como decorrência de um esforço multidisciplinar dentro das organizações. E, finalizando, as Rotinas Organizacionais são apresentadas na perspectiva orgânica, flexível, presentes nas práticas de grupos multi e interdisciplinares que buscam soluções inovadoras através do compartilhamento de seu saberes e saberes-fazer.

\section{1 Compartilhamento do Conhecimento e Gestão da Inovação}

Inovação não é mais resultado de gênios individuais e sim de esforços multidisciplinares envolvendo times de pessoas interagindo em ambientes complexos, intricados e até mesmo caóticos (THAMHAIN, 2003).

O projeto Manhattan de bomba atômica e o programa lunar Appolo são dois exemplos impactantes de como conquistas e descobertas modernas dependem de equipes multidisciplinares de cientistas e engenheiros. E, de forma menos dramática, mas ainda vital para nosso dia a dia, são os desenvolvimentos de softwares e de novos medicamentos (PALETZ e SCHUNN, 2010).

Estes autores apresentam que cientistas têm discutido a diversidade de conhecimento funcionando como uma base mais ampla do pensamento analógico, 
destacando que as lacunas disciplinares devem ser superadas por meio de modelos mentais de compartilhamento para a busca de descobertas científicas. E, no contexto de múltiplos saberes, o conceito de diversidade do conhecimento aborda diversidade como variedade de domínios de especialização.

Também na visão de Clark e Fujimoto (1991), a atuação de equipe multifuncional, que reúne membros de um amplo leque de diferentes atividades organizacionais, é muito eficaz no processo de inovação (apud NONAKA et al., 2001).

A denominação, definição e classificação das empresas como organizações inovadoras ainda é objeto de análise e de estudos, como também a investigação em torno dos processos que promovem e propiciam a inovação é um campo de estudo a ser explorado. A bibliografia de Gestão da Inovação descreve o processo inovador de diferentes formas, sendo senso comum que a dinâmica da inovação pode ser descrita, de forma simplificada, como um processo que percorre pelo menos três etapas principais: invenção (ideação), desenvolvimento (prototipagem e viabilidade) e implementação (difusão e entrega) (BONINI e SBRAGIA, 2011), todas envolvendo grupos de trabalhos nas organizações, podendo haver a participação de indivíduos externos à empresa.

A multidisciplinaridade destes grupos vem sendo associada positivamente às equipes inovadoras pelas amplas possibilidades de acesso à diferentes perspectivas, informações e opiniões. Essa diversidade é resultado da presença de profissionais com conhecimentos e experiências diferentes, tendo em comum altíssimo interesse em buscar novos conhecimentos, assumir riscos e grande habilidade de resolver problemas em um ambiente que propicie e fomente o compartilhamento do conhecimento (THAMHAIN, 2003; PALETZ, 2010; PAROLIN, 2013).

Na gestão de processos de busca de soluções de problemas que envolvem a ampla participação de profissionais multidisciplinares, conflitos podem ser gerados decorrentes da diversidade de conhecimento, por outro lado, a presença ampliada dos diferentes saberes é condição necessária para a inovação. A dinâmica da intensa troca de opiniões e percepções pode provocar conflitos, mas também é um fator que promove soluções inovadoras (PALETZ, 2010). 
Ainda segundo Paletz (2010), em estudos sobre cognição de grupos, a diversidade do conhecimento tem sido associada com a habilidade de geração de analogias, para que haja o alinhamento do entendimento entre os participantes. As analogias geradas somadas às informações, intensamente buscadas pelo grupo, aumentam as possibilidades de pensamentos diferenciados como resultado da multidisciplinaridade.

Quando inovação é associada a gestão do conhecimento, sua inter-relação normalmente é mencionada na análise e no estudo dos processos de troca de saberes e saberes-fazer entre indivíduos, que além de gerarem novos conhecimentos também trazem soluções inovadoras, decorrentes deste processo de soma, combinação e nova categorização do conhecimento (NONAKA et al., 2001).

Ainda segundo Nonaka et al. (2001) o conhecimento é gerado através da interação entre indivíduos com diferentes tipos e conteúdos de conhecimento, processo que é denominado pelo autor como 'conversa do conhecimento'. Neste processo de troca social, a qualidade e a quantidade do conhecimento tácito e explícito dos envolvidos são expandidas, sendo que na fase de combinação, a troca dos conhecimentos explícitos entre as partes pode reconfigurar o conhecimento existente do grupo através da soma, da combinação e da categorização dos conhecimentos individuais. E, na fase seguinte - a de internalização desta reconfiguração - ocorre a atualização de conceitos que podem gerar inovação.

Para Lam (2004), inovação pode ser entendida como um processo de aprendizado e de criação de conhecimento através do qual novos problemas são definidos e novos conhecimentos são desenvolvidos para resolvê-los. Neste contexto, o conhecimento coletivo funciona como base da capacitação organizacional e pode ser interpretado como "conhecimento em estado fluido" que emerge da interação de indivíduos.

A autora apresenta a perspectiva de que o trabalho em grupos integrados promove uma importante fonte de aprendizado e criação de conhecimento, destacando que, na literatura recente, surgem organizações inovadoras formatando estruturas de trabalho em grupos descentralizados como uma das premissas de gestão organizacional. Organizações inovadoras valorizam cada vez mais 
profissionais com prática em resolução de problemas, que tenham intensa habilidade de integração e de compartilhamento de conhecimento através das diferentes unidades organizacionais.

A partir da observação mais atenta quanto a inter-relação dos processos de gestão de conhecimento e de inovação, a diversidade do conhecimento tem sido considerada um fator de importância significativa para potencializar a busca de soluções inovadoras. Schunn (2009) ressalta que equipes de cientistas e de engenheiros - em seus processos de geração de conhecimento - estão cada vez mais multidisciplinares, assim como investidores reconhecem que a resolução de problemas complexos muitas vezes requer equipes de várias disciplinas. No universo acadêmico, universidades estão continuamente desenvolvendo programas interdisciplinares e, da mesma forma, no âmbito social (organizacional). Schunn (2009) destaca que o conhecimento diversificado tem sido apontado como um fator positivo na inovação equipe, mas a tentativa de entender seus efeitos ainda não conseguiu encontrar resultados consistentes.

Almeida et al. (2008) também ressaltam que o compartilhamento do conhecimento de diferentes partes da empresa, tem importante valor para gerar resultados em inovação. Em seus estudos, foi ressaltada a importância de diferentes tipos de conhecimento para determinar padrões de integração que gerem soluções inovadoras: resoluções de problemas bem-sucedidas estão normalmente associadas a bases múltiplas de conhecimento - pesquisadores, consumidores, engenheiros, designers - que formam equipes capazes de acessar experiências paralelas e estimular o pensamento criativo.

Empresas que têm a capacidade de mobilizar profissionais de diferentes partes com saberes diversos, e acessar diferentes recursos para atingir suas metas estratégicas, são empresas que conseguem integrar conhecimento, aprender e inovar (HEDBERG e WOLFF, 2001).

Diante do exposto, a multidisciplinaridade é uma característica quase que mandatória aos grupos de trabalho envolvidos em desafios para a inovação. As organizações assumem cada vez mais que precisam sair da zona de conforto criadas por práticas e regras formalizadas para alcançarem resultados eficientes e partirem para a institucionalização das práticas de compartilhar conhecimentos 
entre as mais variadas fontes: desde seus diversos profissionais até outras organizações, passando eventualmente pelos próprios clientes ou consumidores.

Todo e qualquer grupo é diverso. A partir do entendimento de que a gestão da diversidade destes grupos está diretamente relacionada à possibilidade do novo, cabe à Gestão da Inovação promover no contexto organizacional a integração das diferenças para que não só novos produtos e serviços sejam desenvolvidos, mas novos caminhos e pensamentos sejam sempre experimentados.

\section{2 \\ Competências Coletivas}

Este tópico do referencial teórico foi dividido em três partes: conceitos, configuração e gestão das competências coletivas. As perspectivas que podem contribuir com este estudo abrangem desde a contextualização da competência nas empresas, evoluindo para a forma como elas se organizam em cada um destes contextos, chegando aos fundamentos dos modelos de gestão de competências a serem considerados para a busca de solução inovadora.

\subsection{1 \\ Conceitos e definições}

Em 1990, Prahalad e Hamel contextualizaram competências como "a cola que liga os negócios existentes e o motor que desenvolve novos negócios”, sendo core competences "o aprendizado coletivo da organização, especialmente no processo de coordenar diversas habilidades e integrar múltiplos fluxos de tecnologias". Para os autores, esse ativo não material das organizações aumenta à medida que é aplicado e compartilhado (PRAHALAD e HAMEL, 1990, p. 81) podendo tornar-se um dos pilares de competitividade da empresa.

Até este momento, a competência no contexto organizacional era apresentada por diversos autores com uma abordagem estratégica que comparava os pontos fortes da empresa perante a concorrência, não considerando a análise das capacidades internas à organização, inclusive a core competence, como constituintes de sua vantagem competitiva. (RUAS, SILVA, BECKER e COMINI, 2013). 
Pesquisadores franceses como Retour e Krohmer (2011), Colin e Grasser (2011) e Michaux (2008) conceituam competências coletivas de forma mais explícita, uma vez que entendem que esta dimensão coletiva, de grupo, pode completar a lacuna existente entre competências individuais e competências organizacionais (RUAS et al., 2013). Essa lacuna, sob o olhar da gestão, pode estar relacionada à tangibilização de tais competências, que Colin e Grasser (2011) defendem ser mais evidente para as competências individuais e organizacionais, uma vez que ambas podem ser associadas a resultados visíveis resultantes da mobilização de diversas capacidades atribuídas aos indivíduos ou à organização. A percepção dos resultados no âmbito coletivo, segundo os autores, não apresenta a mesma visibilidade, por suas características imprecisas e definidas a partir de relações informais, tanto funcionais como emocionais, sempre dentro de um contexto, de um período e com uma finalidade específica. $\mathrm{Na}$ observação destas situações coletivas de trabalho, a competência coletiva se configura através de "complementaridades, sinergias, cooperações ou cumplicidades que fazem com que a competência do grupo chegue a um nível superior ao da soma das competências individuais" (COLIN e GRASSER, 2011, p. 80).

Retour e Krohmer (2011) buscam demonstrar que, em uma organização, "a apropriação das competências coletivas nasce do desenvolvimento das competências individuais", como também constatam que as competências fundamentais (core competences) são resultados da "combinação de competências coletivas exploradas em serviços internos e/ou no interior de diversos departamentos da empresa" (RETOUR e KROHMER, 2011, p. 46).

Para Michaux (2008), os processos mobilizadores da competência coletiva seriam resultantes de duas bases: a social, que configuram a interação e compartilhamento entre indivíduos e grupo; e a estratégica, que são os processos de direcionamento e acompanhamento coletivos. Esta articulação entre as perspectivas social e funcional, reforça o papel da interação na dinâmica processual das competências coletivas (RUAS et al., 2013, apud MICHAUX, 2008). Le Bortef (2003) explicita que é muito "difícil decodificar a alquimia que faz com que uma competência coletiva se desenvolva e que um grupo alcance bons resultados" (Le Bortef, 2003, p. 116) 
Essa alquimia pode estar na evidência, segundo Ruas et al. (2013), de que a interação é consenso entre os autores citados, quando a configuração da dimensão coletiva é pesquisada. Sob a perspectiva da interação, os autores classificam as competências como individuais e coletivas. As individuais são associadas às atividades, tanto de profissionais como de líderes; e as coletivas referem-se aos grupos responsáveis por projetos ou por uma atividade principal de uma área e aos grupos que promovem a interação de diferentes funções, inserindo esta competência no plano estratégico (RUAS et al., 2013). Neste plano estratégico, pode-se tentar analisar uma vantagem competitiva através da perspectiva de Le Boterf (2003): a competência de uma empresa ou de um departamento não corresponde à soma das competências individuais, sendo que seu valor está além dos elementos constituintes destas competências, mas "da qualidade da combinação ou da articulação entre esses elementos" (LE BOTERF, 2003, p. 229), ambas peculiares a cada organização.

Visando encontrar parâmetros para um senso comum quanto à definição de competências coletivas, Retour e Krohmer (2011), a partir de uma coletânea de definições de competência coletiva de vários autores, buscaram examinar a perspectiva de cada um, como também as concepções similares ou comuns. Desta análise, os autores apresentam duas acepções diferentes e complementares: a primeira seria um saber-fazer operacional existente em um grupo que traz um desempenho não alcançável por um indivíduo ou pela soma das competências individuais; e, a segunda constata que os profissionais que trabalham em grupo, ou que estabelecem algum tipo de troca com outros profissionais formal ou informalmente, criam uma competência coletiva - um saber comum a todos - que é tangibilidade no momento em que as ações individuais são realizadas integradamente para o desenvolvimento do trabalho do grupo. (RETOUR e KROHMER, 2011).

\subsection{2}

\section{Configuração das Competências Coletivas}

Quando se analisa as definições do conceito de competências coletivas, depara-se com um conjunto de características fundamentais que possuem configurações comuns, mas ainda não solidificadas o suficiente para que emerja 
uma definição de senso comum. No contexto acadêmico, são apresentadas várias possibilidades de construção de entendimento do conceito de competências coletivas percebendo a pouca articulação entre esta teoria e a prática nas organizações (SILVA, 2012).

Ruas et al. (2013) constatam que existem três elementos recorrentes em suas análises das dimensões de entendimento e conceituação de competências coletivas: os processos de interação, os atributos e os elementos facilitadores de sua gestão.

Considerando a interação como o processo principal que conceitua competência coletiva, Zarifian (2001) apresenta um novo tipo de relação entre indivíduo e coletivo onde, apesar da singularidade individual, as atividades profissionais continuam sendo coletivas. Desta forma, o coletivo pode ser visto como um conjunto de individualidades que deve regular suas interações e relações para compor suas complementaridades. Tal processo e tal aprendizado deve emergir dos próprios indivíduos, da "auto-regulação de suas interações no interior de um grupo profissional aberto", que se tornam competentes no contexto de uma vida coletiva (ZARIFIAN, 2001, p. 107).

Ainda na perspectiva de interação, Le Bortef (2003) aborda que, no gerenciamento de processos recorrentes ou de projetos com período de desenvolvimento definido, o encadeamento das atividades e os fluxos de informações que os permeiam e os conectam podem gerar uma significativa integração dos saberes e das competências envolvidas. Considerando este movimento orgânico, o autor defende que a empresa, em sua totalidade, pode ser considerada um "sistema de competências" desenvolvendo uma configuração fundamentada no conceito de rede onde a relação entre vários saberes e saberesfazer de diferentes atividades pode constituir e organizar uma empresa como uma rede de competências. Para o autor, "a competência coletiva é uma competência em rede" (LE BORTEF, 2003, p. 231).

As competências coletivas são constituídas, para Retour e Krohmer (2011), por quatro atributos fundamentais: o referencial comum, a linguagem compartilhada, a memória coletiva e o engajamento subjetivo.

O referencial comum trata-se de uma representação identificada pelo grupo, que é construída em função das informações detidas pelos indivíduos do coletivo e deve ser considerado o resultado de um trabalho de elaboração coletiva (RETOUR 
e KROHMER, 2001). Esta referência conhecida por todos viabiliza o compartilhamento das competências de cada um, sendo efêmera e transitória, uma vez que sua elaboração é realizada pelos envolvidos na preparação e realização das ações para atingirem os objetivos a serem alcançados naquele contexto onde o grupo está inserido.

Para os autores, a linguagem comum, o segundo atributo das competências coletivas, refere-se aos códigos de comunicação entre os membros do grupo que permitem que a conversa ocorra através de meias palavras, enunciação abreviada e significados encontrados nas entrelinhas. O terceiro atributo - a memória coletiva - é construído pelos processos de aprendizagem do grupo que podem ocorrer de forma harmônica ou através de confrontos dos saberes-fazer dos indivíduos gerando um saber-fazer comum que passa a ser dominado pelos membros deste grupo. Ainda através das interpretações dos problemas pelo grupo, chega-se a uma interpretação comum que também poderá constituir a memória coletiva de uma equipe de trabalho.

Por último, o atributo engajamento subjetivo, que segundo Retour e Krohmer (2011), ocorre quando o grupo percorre as etapas necessárias para a resolução de problemas e os indivíduos tomam iniciativas com certa autonomia e responsabilidade, visando o enfrentamento das dificuldades a serem superadas e para encontrarem as melhores soluções dos problemas.

E, complementando os atributos da competência coletiva definidos por Retour e Krohmer (2011), Colin e Grasser (2011) sugerem que ainda outros três atributos que a constitui: a competência coletiva resulta de uma aprendizagem, da heterogeneidade do grupo, e do aspecto dinâmico.

A partir da realização do trabalho por uma equipe, as capacidades do grupo melhoram como decorrência do processo de aprendizagem, de compartilhamento de modelos de ações e transmissões de rotinas. A heterogeneidade do grupo traz saberes e saberes-fazer que permitem ampliar os recursos cognitivos. E, a troca que ocorre entre os membros destes grupos - e "que norteia as ações comuns é de natureza muito mais multilateral do que bilateral" - promove uma rede de relações que reforça o caráter coletivo da competência produzida e incorporada ao grupo: cada indivíduo é fonte e receptor de aprendizagem. Assim, pela variação das formas de fazer, pela diversidade das pessoas e suas competências, e das 
formas de intercâmbio entre os membros do grupo, a produção e a transformação da competência coletiva são permanentes e contínuas, tornando-a perene para além da mudança de membros da equipe (COLIN e GRASSER, 2001, p. 94).

\subsection{3}

\section{Gestão das Competências Coletivas}

O modelo de gestão por competências tem sido adotado de forma recorrente no ambiente organizacional, porém esta abordagem já não recebe o mesmo destaque no mundo acadêmico brasileiro. Internacionalmente o debate sobre competências apresenta perspectivas multidimensionais na gestão de capacidades organizacionais e interorganizacionais (RUAS, FERNANDES, FERRARI e SILVA, 2010) discutindo os conceitos e composições das competências individuais, organizacionais e coletivas.

Retour e Krohmer (2011), após a análise de várias definiçõos e conceitos de competência coletiva, mostram que as fontes de criação destas competências são: os elementos próprios às pessoas e os fatores organizacionais. Os autores definem quatro elementos próprios às pessoas: a) o capital das competências individuais que destaca a importância dos pontos fortes de cada indivíduo; b) as interações afetivas que permitem a constituição de uma comunidade; c) as relações informais que promovem trocas no contexto cotidiano e geram "as maneiras de ser, de pensar, de raciocinar, de interpretar a realidade e agir"; e, d) a cooperação que permite uma compreensão comum sobre os problemas a serem resolvidos. Junto a estes elementos individuais, quatro fatores organizacionais irão desenvolver as competências coletivas: a) a composição das equipes definida pelo líder; b) as interações formais que definem as responsabilidades; c) o estilo de administração delimitando o grau de autonomia dos membros e definindo os objetivos do grupo; e, d) os fatores mobilizadores de competências coletivas associados à Gestão de Recursos Humanos (RETOUR e KROHMER, 2011, p. 52). Para estes autores, a integração dos elementos próprios às pessoas e os fatores organizacionais geram resultados decorrentes da melhor articulação, interação e gestão dos mesmos.

A reunião e mobilização de competências podem criar "novos campos de valor", segundo Zarifian (2001). Cada grupo de trabalho organizado para o desenvolvimento de diferentes projetos ou desafios, composto por suas 
competências individuais, pode criar de maneira simples e dinâmica um campo de valorização. Ou seja, de geração de novos valores (ZARIFIAN, 2001) para a empresa.

Refletindo sobre a relação entre competências e criação de valor em um coletivo, Zarifian (2001) apresenta o conceito de "plasticidade" das competências. Diferente de flexibilidade, a plasticidade permite que a competência se reformule de acordo com as oportunidades e mudanças dos contextos profissionais. Nesta perspectiva, a competência abandona a lógica tradicional da ocupação - regras rígidas em um ambiente fechado - para uma abordagem aberta da ocupação, onde a competência distingue-se por ser capaz de ser recompor face a novas situações. Para o autor, é com “apoio em conhecimentos profundos em áreas técnicas, que demandam sólidas capacidades de aprendizagem e generalização, e em um comportamento aberto à inovação, que a plasticidade pode ser desenvolvida" (Zarifian, 2001, p. 100).

Segundo Molon e Silva (2012), são as competências coletivas "que asseguram a realização da missão, da visão e/ou da estratégia da empresa. Elas constituem o resultado de um processo e não sua causa", o que pode nortear a atenção para "o aprender, o fazer e o entender" da ainda complexa gestão de competências coletivas nas organizações (MOLON e SILVA, 2012, p.11).

Uma vez que competência coletiva emerge organicamente da sinergia das competências individuais, não como resultado da soma destas, mas sim da agregação de valor de cada uma ao coletivo (Le Bortef, 2003), pode-se observar que esses novos saberes-fazer são descritos como resultantes de uma combinação harmoniosa entre talentos individuais, fatores organizacionais e um estilo de gestão (RETOUR et al., 2011) e trarão para a organização uma maior capacidade de resolver problemas.

A relação entre indivíduo, rotinas e mudanças organizacionais pode ir ao encontro a abordagem na qual compartilhar competências individuais nas rotinas de inovação pode trazer mudança dos resultados - a melhoria, a diferenciação e eventualmente o novo - o que parece fomentar o aprendizado organizacional e sua resultante evolução dos modelos de gestão organizacionais (FELDMAN E PENTLAND, 2003).

Diante de tais abordagens, pode-se considerar a relação entre a multidisciplinaridade presente em equipes que buscam soluções inovadoras e a 
gestão de competências coletivas como um indicador determinante para a construção de saberes que geram inovação. Aprendizado, entendimento, engajamento e criação de novos potenciais valores são pontos comuns nos respectivos processos de interação e integração de saberes e saberes-fazer e estão diretamente ligados não só à gestão dos recursos humanos da empresa, como também à gestão da inovação.

As competências individuais são constituintes dos recursos humanos e a integração de tais competências desenvolve organicamente dentro da empresa um saber coletivo que promove novas possibilidades de processos, soluções e resultados que trazem diferenciais competitivos para uma organização.

\section{3 \\ Rotinas Organizacionais}

Modelos, regras e procedimentos definidos para a realização de atividades de trabalho facilitam os processos de gestão nas organizações que buscam resoluções de problemas, buscam administrar conflitos, superar desafios e alavancar oportunidades de negócios. Ao longo das últimas décadas, o conceito de rotinas organizacionais é estudado e discutido por diferentes autores, sob diferentes perspectivas, e considerando as características das atividades, dos indivíduos e dos ambientes onde estão inseridos interna e externamente (PARMIGIANI e HOWARD-GRENVILLE, 2011).

A partir do entendimento destes fundamentos, os autores definem rotinas organizacionais como "padrões repetitivos das ações interdependentes de uma organização" (PARMIGIANI e HOWARD-GRENVILLE, 2011, p. 417). Esta definição se apresenta coerente às duas correntes de estudos por eles observadas: Capacidades e Prática. A primeira considera as rotinas como "entidades" que buscam alcançar os objetivos e metas da empresa. Já a segunda se preocupa em entender a prática cotidiana das rotinas: como são estabelecidas, realizadas, modificadas no dia a dia organizacional.

A perspectiva Capacidades tem origem na economia organizacional e está associada ao desempenho organizacional, sendo classificada como ordinárias, quando associadas às operações básicas, ou como dinâmicas, quando envolvem criação e algum tipo de mudança. Segundo Parmiagini e Howard-Grenville 
(2011), como as rotinas são sustentadas por ambas - ordinárias e dinâmicas, elas podem promover tanto estabilidade, quanto mudanças no ambiente corporativo.

Os autores apresentam a perspectiva Prática fundamentados no conceito de organizing, atividade diária de organizar (PARMIGIANI e HOWARDGRENVILLE, 2011, apud FELDMAN e ORLIKOWSKI, 2011), e assim, as rotinas são analisadas a partir de uma visão prática sobre o funcionamento interno de contextos organizacionais específicos. Em contraponto com a perspectiva Capacidades, a Prática considera que as dinâmicas internas das rotinas sofrem o agenciamento dos indivíduos por meio de suas realizações cotidianas nos contextos organizacionais e são classificadas: como emergentes, por serem decorrentes do desempenho destes atores, e como generativas, por possuírem em suas dinâmicas internas as "sementes" de sua continuidade ou mudança (FELDMAN e PENTLAND, 2003).

Em 2003, Feldman e Pentland defenderam uma nova Teoria de Rotinas Organizacionais, através da visão de que as rotinas podem ser responsáveis pela inércia ou inflexibilidade de uma organização, mas também podem ser importante fonte de flexibilização e mudança. A partir da literatura consultada para o desenvolvimento da teoria, eles apresentaram sua definição para rotinas organizacionais: "um padrão repetitivo de ações interdependentes, envolvendo múltiplos atores" (FELDMAN e PENTLAND, 2003, p. 96).

Como um fenômeno social, as rotinas possuem dualidade entre estrutura e agenciamento, sendo a primeira a ideia abstrata - o esquemático da rotina, e a segunda o desempenho da rotina por "um indivíduo específico, em um momento específico, em um lugar específico", a rotina em prática. Estrutura e ação (agenciamento) fundamentam os aspectos constitutivos das rotinas organizacionais: ostensivos e performativos; e a relação entre estes aspectos é responsável por promover a criação contínua de oportunidades para evolução, escolha e adoção de diferentes práticas e padrões de ações, como também permite que elas gerem uma significativa melhoria dos resultados organizacionais (Feldman e Pentland, 2003, p. 95).

Para os autores, ambos aspectos das rotinas são mutuamente necessários. Sem o aspecto ostensivo não é possível nomear e até mesmo enxergar os padrões das atividades, ao passo que sem os aspectos performativos, as rotinas não são realizadas. Contextualizando o equilíbrio necessário entre estes aspectos, Feldman 
e Pentland (2003) ressaltam, por exemplo, que superestimar a importância do ostensivo pode levar os líderes a subestimar a importância de ajustes e improvisações que os indivíduos fazem na realização de suas atividades performativas. Outro destaque é a observação de que a interação de ambos os aspectos pode trazer mudanças: aspectos de improviso e evolução, quando os indivíduos fazem coisas novas por influências externas, ou pela reflexão de suas atividades, eles alteram o repertório de atividades, criando e recriando os aspectos ostensivos das rotinas.

Abordando o aspecto performativo das rotinas realizadas pelos indivíduos em um contexto de trabalho de grupo, vale observar que Dionysiou e Tsoukas (2013) em seus estudos sobre a perspectiva da interação simbólica por dentro das rotinas organizacionais, apresentam o conceito defendido por Mead, em 1934: "eu individual é desenvolvido em um profundo senso do todo do qual faz parte e no qual interage para a atividade conjunta." A partir deste conceito, os autores apresentam a interação simbólica, dentro das rotinas realizadas por um conjunto de indivíduos, como constituinte do processo pelo qual os significados são gerados, compartilhados, mantidos e alterados. Esta natureza "open ended" dos aspectos simbólicos da interação caracteriza o momento presente como aquele que possibilita a novidade e, nos momentos presentes durante as ações individuais e conjuntas, o novo pode surgir. (DYONISIOUS e TSOUKAS, 2013, p. 187)

Tsoukas e Chia (2002) descrevem, em seu estudo sobre mudanças organizacionais, que empresas que se comportam de forma previsível, à luz de regras e normas rígidas perdem a habilidade de refletir, de criar conexões metafóricas e de improvisar para buscar soluções, dificilmente conseguem adaptar suas ações às diferentes demandas que surgem. Organizações que se inserem em um mundo "open-ended" permitem que os indivíduos vivenciem novas experiências e tenham a habilidade de refletir para fazerem novas conexões metafóricas para gerarem mudanças, evoluções e inovações das práticas organizacionais.

Na perspectiva de um ambiente "open-ended”, Dionysiou e Tsoukas (2013) enfatizam que a natureza aberta e flexível das ações individuais e do grupo de trabalho permite que todos percebam que "a realidade é um processo caracterizado pela constante possibilidade de novo" (DIONYSIOU e TSOUKAS, 2013, p. 188). Neste contexto, a novidade pode surgir através de uma excepcional experiência, 
caracterizada pela ausência de um comportamento automatizado por procedimentos e rotinas, onde as reflexões dos indivíduos e do grupo são exercitadas para encontrar o novo. Para os autores, as interações simbólicas contribuem para a recriação de rotinas. Assim, o processo reflexivo que pode gerar mudanças nas rotinas e procedimentos para produzir um novo sentido compartilhado pelo grupo, poderia ser considerado como mais uma das características de um padrão de pensamento coletivo para busca de solução de problemas. (BITTENCOURT e KLEIN, 2012).

Para Hoeve e Nieuwenhuis (2006), rotinas são padrões coletivos recorrentes que descrevem o que é feito, por quem e porquê, que funcionam como esquemas para o entendimento e comportamento dos indivíduos envolvidos nas ações. Elas fornecem referências individuais que conectam as pessoas ao coletivo e, simultaneamente, o coletivo com a organização como um todo servindo como mecanismo de interação entre diferentes níveis da organização. Assim, para os autores, uma vez que uma organização é um conjunto de rotinas, a inovação pode ser definida como a mudança destas rotinas que devem ser aplicadas em contextos de desafios, mudanças ou soluções de problemas. P. 184

Diante do exposto, uma gestão organizacional focada em inovação, deve considerar a complexidade da dinâmica das rotinas organizacionais, suas classificações e seus aspectos constitutivos para alavancar sua capacidade competitiva através da inovação. A dinâmica orgânica da integração e interação de competências que ocorre em grupos de trabalho que busca soluções inovadoras sugere que as rotinas de inovação que as suportam são flexíveis e passíveis de evolução constante por serem da ordem da desconstrução de definições, da experimentação, do exercício do pensamento coletivo para encontrar uma nova forma de resolver um problema, gerando uma nova solução. 


\section{3 \\ Metodologia}

O estudo de pesquisa apresentado nesta dissertação tem como objetivo entender como os indivíduos vivenciam (ou experimentam) o compartilhamento das competências individuais nas rotinas/processos de busca de solução inovadoras. Para alcançar os objetivos primário e secundário do estudo foi adotado como procedimento de pesquisa o método Fenomenográfico.

Este capítulo apresenta a concepção e estratégia da pesquisa, a descrição do método adotado, suas características, os desafios e delimitações na sua adoção e o processo de coleta dos dados: definição da amostra e processo de coleta dos dados durante as entrevistas realizadas.

\section{1 Concepção e estratégia da pesquisa}

A abordagem qualitativa foi escolhida para este estudo, uma vez que a concepção filosófica proposta é construtivista e, assim, buscou entender a visão que os participantes possuíam da situação que estava sendo estudada (CRESWELL, 2010), com vistas a gerar significado a partir dos dados coletados no campo.

Creswell (2010) descreve a pesquisa qualitativa como um meio que possibilita explorar e entender o significado que o indivíduo ou os grupos atribuem a um problema social ou humano. Os pesquisadores que adotam essa forma de investigação apoiam uma pesquisa de estilo indutivo, com foco no significado individual e relevância da interpretação da complexidade de uma situação.

Segundo Denzin e Lincoln, 1994 (apud CHERMAN, 2013), a pesquisa qualitativa envolve uma abordagem interpretativa sobre o assunto abordado, cabendo ao pesquisador construir sentido ou interpretar o fenômeno em termos dos significados que os indivíduos apresentam acerca do fenômeno (apud 
CHERMAN, 2013), possibilitando que apresente o ponto de vista, a experiência e o valor percebido em relação ao fenômeno estudado.

\section{2 \\ Método de Pesquisa}

Este capítulo apresenta a justificativa da escolha do método de pesquisa adotada, assim como as etapas de pesquisa realizadas neste estudo, considerando que este trabalho se propõe a observar e entender como profissionais percebem e experimentam o fenômeno de compartilhar competências para buscar a inovação.

\subsection{1}

\section{A escolha método}

Adota-se neste estudo o Método Fenomenográfico que considera, segundo Marton (1991), as diferentes percepções dos indivíduos sobre um fenômeno, considerando a experiência vivida pelo indivíduo em um determinado contexto. Para Cherman (2013), o método parte "da percepção acerca da experiência prática, que é retomada e revivida no momento das entrevistas" (CHERMAN, 2013, p. 104), uma vez que este método busca investigar, descrever, analisar e entender as diferentes formas de como o fenômeno estudado é experimentado pelos entrevistados através de seus relatos e suas narrativas (MARTON e BOOTH, 1997)

Ainda na perspectiva apresentada por Cherman (2013), o método Fenomenográfico foi escolhido para o presente trabalho por ajudar a descobrir como os indivíduos vivenciam e experimentam o compartilhamento do conhecimento durante a busca de soluções inovadoras de problemas.

\subsection{2}

\section{Características do Método}

No método fenomenográfico, o pesquisador busca identificar as formas como o fenômeno estudado é experimentado de acordo com a descrição feita pelos entrevistados, sendo a unidade pesquisada, a forma que se experimenta um dado fenômeno, e o objeto da pesquisa, a variação destas formas de experimentar este 
fenômeno. O propósito deste método é, além de descrever e identificar as formas como os fenômenos são vividos e experimentados, agrupar (categorizando) as variações das percepções individuais, sem deter-se na explicação dessa variedade (MARTON e BOOTH, 1997; MARTON, 1981).

A Fenomenografia considera os aspectos estruturantes da consciência durante a experiência do indivíduo em relação ao fenômeno estudado, segundo Marton e Booth (1997) que apresentam os elementos "Como" e "O quê": o "Como" descreve a ação envolvida na experiência e o "O que" descreve o objeto da ação. No presente trabalho, o "como" seria o processo de compartilhar conhecimento para buscar soluções inovadoras e o "o que" representa o surgimento da solução inovadora como decorrência do compartilhamento de conhecimentos.

Como cada indivíduo experimenta um fenômeno a partir de seu discernimento pessoal dentro do contexto que está inserido; o método, a partir dos relatos dos entrevistados, descreve as variações entre as diferentes formas de como o fenômeno foi experimentado. Essas variações derivam-se do fato que existem diferentes aspectos e partes do fenômeno como um todo que recebem variados focos de atenção por parte dos entrevistados, gerando diversas concepções acerca do fenômeno (Marton e Booth, 1997).

\subsection{3 \\ As perspectivas de segunda ordem: experimentar o objeto}

Fenomenografia "é orientada para as formas de experimentar os diferentes fenômenos, nas formas de enxergá-los, conhecer sobre eles e adquirir habilidades relacionadas a eles". (MARTON e BOOTH, 1997, p.117), tentando entender os aspectos críticos das formas de experimentar o mundo que tornam as pessoas capazes de lidar com ele de maneira mais ou menos eficiente.

Segundo os autores, a perspectiva de primeira ordem possibilita observações sobre o mundo como é descrito pelos indivíduos, ou seja, "uma declaração sobre a realidade" (MARTON e BOOTH, 1997). Na análise das percepções dos indivíduos, a perspectiva de segunda ordem considera as formas de experimentar o mundo, os fenômenos e as situações onde se encontram os objetos de pesquisa, apresentando as declarações sobre as ideias dos indivíduos sobre esta realidade. (MARTON e BOOTH, 1997; CHERMAN, 2013). 
A pertinência deste método para o presente estudo está em sua abordagem de que experiências são refletidas nas demonstrações sobre o mundo, dentro de atos praticados, em artefatos produzidos. Ao adotar uma perspectiva de segunda ordem, tem-se que colocar entre parênteses tais julgamentos; tem-se que olhar para as declarações, atos, e artefatos para descobrir "quais formas de vivenciar aspectos particulares do mundo refletem, independentemente da validade, habilidade, ou a funcionalidade. Tal como a busca deve ser realizada à luz das outras coisas que sabemos sobre as formas de experimentar o mundo das pessoas. (Marton e Booth, 1997, p. 120).

\subsection{4}

\section{Desafio: descrever as variações das experiências}

Marton e Booth (1997) apresentam o objeto de pesquisa fenomenográfica como os diferentes modos de se vivenciar/experimentar um fenômeno, sendo o interesse primário do método a descrição desta variação.

Esta variação de experiências é organizada em categorias, sendo que o princípio básico da fenomenografia é que "qualquer que seja o fenômeno que nos deparamos, ele é experimentado em um número limitado de formas qualitativamente diferentes" (MARTON e BOOTH, 1997). Os autores consideram "experiência" como "uma relação interna entre pessoa e mundo (ou algo do mundo)" colocando que "estamos cientes de tudo ao mesmo tempo, ainda que não na mesma maneira.” (MARTON e BOOTH, 1997, p. 122)

Vale ressaltar que o objetivo do estudo é analisar e descrever a variação das experiências individuais, organizando-as em categorias qualitativamente distintas, das formas de vivenciar o fenômeno em questão, independentemente se as diferenças são diferenças entre indivíduos ou para um mesmo indivíduo (Marton e Booth, 1997). Os autores referem as categorias de descrição ao nível coletivo, lembrando que embora o fenômeno descrito (as formas de experimentar alguma coisa) e a descrição (as categorias de descrição) sejam extremamente interligados, a descrição nunca representa a totalidade do que é descrito, assim como a forma de experimentar nunca representa mais do que uma parte do fenômeno experimentado. 
Marton e Booth (1997) definem três critérios das categorias descritivas do Espaço Resultado ou Outcome Spac): a. categorias que compõem a análise são de clara relação com o fenômeno investigado a ponto de cada uma nos dizer algo distinto sobre uma forma particular de experimentar o fenômeno; b. categorias que possuem uma relação lógica umas com as outras e frequentemente organizadas de forma hierárquica; c. um sistema parcimonioso que permita que as categorias expliquem como pode ser viável e razoável para capturar as variações significativas dos dados coletados.

A organização do Espaço Resultado é, segundo Cherman (2013), um dos produtos do método Fenomenográfico. A autora cita Bowden (2005, apud CHERMAN, 2013) quando considera que os indivíduos transitam por esta estrutura organizada no Espaço Resultado, “à medida que experimentam repetidamente o fenômeno e aprendem a experimentá-lo de diferentes maneiras. " (MARTON e BOOTH, 1997).

Durante as entrevistas orientadas por um roteiro semiestruturado, a pesquisadora buscava enfatizar a importância de que fossem colocadas as percepções e experiências vividas pelo entrevistado nas situações que estavam sendo usadas como exemplo ou como referências análogas ao fenômeno de compartilhar competências para busca de soluções inovadoras.

A maioria dos entrevistados teve facilidade em expressar o que percebem e sentem sobre o fenômeno explorado, apesar de que em alguns momentos os entrevistados tentavam descrever os acontecimentos relacionados ao fenômeno, enfatizando problemas e oportunidades que os modelos de gestões de inovação e organizacionais incorrem e desperdiçam. Porém, uma vez que a entrevista era conduzida para extrair tais percepções, o campo se configurou como uma ampla fonte de percepções, vivencias e sentimentos acerca do fenômeno com ênfases, destaques e figuras de expressão diversas e peculiares, o que proporcionou a possibilidade de uma rica análise e interpretação fenomenográfica.

Mesmo que o campo tenha apresentado diversas narrativas e diferentes expressões acerca do tema, confirmou-se a característica do método fenomenográfico de que a variação das percepções dos indivíduos sobre o fenômeno não é ampla e, em determinado momento, ocorreu o saturamento da pesquisa: os entrevistados começam a responder da mesma forma como os entrevistados anteriores o fizeram. Apesar da semelhança das respostas, todas 
foram consideradas, analisadas e interpretadas pois a experiência individual, mesmo que parecida com a maioria, quando contextualizada em grupos de trabalho traz novas perspectivas decorrente das peculiaridades dos grupos e das organizações onde estão inseridos.

\section{2 .5}

\section{Limitações do Método}

A presença do pesquisador e sua potencial influência na coleta e na análise dos dados pode ser um ponto crítico do estudo, limitando-o, uma vez que o método de coleta de dados utilizado foi baseado em entrevistas semiestruturadas.

Entretanto, vale ressaltar que as categorias de descrições definidas no processo da metodologia Fenomenográfica referem-se ao âmbito coletivo. Assim, embora o descrito (a forma de experimentar algo) e a descrição (categorias) são irrestritamente interligados, a descrição nunca é a totalidade do que ela descreve, como a forma de experimentar nunca é mais do que parte do fenômeno experimentado.

\subsection{6}

\section{Amostra Intencional}

A pesquisa foi realizada junto a profissionais que atuam na área de Marketing e Comunicação de Marketing, em organizações de diferentes portes (pequeno, médio e grande), buscando aqueles que participam de processos ou rotinas que reúnem grupos intra e interorganizacionais para busca de soluções inovadoras.

O campo deste estudo foi realizado da seguinte forma:

- Em 10 empresas nacionais ou multinacionais de diferentes setores da economia (Mineração, Seguro, Moda, Design, dentre outros), com mais de 50 funcionários, com sede no Rio de Janeiro e em São Paulo.

- Em cada empresa, foram entrevistados em média 2 profissionais com os seguintes perfis: líder com nível gerencial médio, líder com nível de coordenação ou supervisão e/ou profissional sênior envolvidos em 
algum tipo de processos ou rotinas de busca de soluções inovadoras de problemas.

\begin{tabular}{|c|c|c|c|c|c|c|c|}
\hline & Genero & Idade & Segmento & Porte $(*)$ & Depart / Área & Cargo & Área de For maçao \\
\hline 1 & M & 28 & Conteúdo Entretenimento & G & Novas Mídias & Analista de Marketing Sr & Administração \\
\hline 2 & $\mathrm{~F}$ & 27 & Conteúdo Entretenimento & G & Marketing & Analista de Marketing PI & Comunicação Social_Publicidade \\
\hline 3 & $\mathrm{~F}$ & 29 & Oil \& Gas & G & Marketing & Analista de Desenvolvimento Pl & Engenharia de Alimentos \\
\hline 4 & $\mathrm{~F}$ & 36 & Oil \& Gas & G & Marketing & Analista de Desenvolvimento $\mathrm{Sr}$ & Comunicação Social_Publicidade \\
\hline 5 & $\mathrm{M}$ & 37 & Bem-estar e lazer 4000 & $\mathrm{M}$ & Marketing Bodytech & Gerente de Marketing Digital & Propaganda e Marketign \\
\hline 6 & $\mathrm{~F}$ & 31 & Bem-estar e lazer 4000 & $\mathrm{M}$ & Marketing Proforma & Gerente de Marketing & Publicidade \\
\hline 7 & $\mathrm{M}$ & 42 & Varejo_Moda & $\mathrm{M}$ & Design & Coordenador de Design & Desenho Industrial (Design Grafico) \\
\hline 8 & $\mathrm{~F}$ & 36 & Varejo_Moda & $\mathrm{M}$ & Marketing & Analista de Marketing Sr & Administraçao_Marketing \\
\hline 9 & $\mathrm{~F}$ & 38 & Mineração & G & Comunicação Corporativa & Especialista de Comunicação & Comunicação Social_Publicidade \\
\hline 10 & $\mathrm{~F}$ & 31 & Mineração & G & Comunicação Corporativa & Analista de Comunicacao Pl & Comunicação Social_Jornalismo \\
\hline 11 & $\mathrm{~F}$ & 48 & Varejo_Jóias & M & Comercial_Visual Merchan & Coordenadora de Visual Merchandising & Desenho Industrial (Design Grafico) \\
\hline 12 & $\mathrm{~F}$ & 30 & Varejo_Jóias & $\mathrm{M}$ & Comercial_Visual Merchan & Aanlista de Visual Merchandising & Desenho Industrial (Design de Produto) \\
\hline 13 & $\mathrm{~F}$ & 40 & Conteúdo Jornalistico & G & Marketing & Coordenadora de Marketing & Comunicação Social_Publicidade \\
\hline 14 & $\mathrm{~F}$ & 31 & Conteúdo Jornalistico & G & Comunicacao Interna - $\mathrm{RH}$ & Gerente de Comunicação Interna & Comunicação Social_Jornalismo \\
\hline 15 & $\mathrm{M}$ & 32 & Conteúdo Jornalistico & $\mathrm{P}$ & Conteúdo & Editor Chefe & Comunicação Social_Jornalismo \\
\hline 16 & $\mathrm{~F}$ & 31 & Conteúdo Jornalistico & $P$ & Conteúdo & Editora & Comunicação Social_Jornalismo \\
\hline 17 & $\mathrm{~F}$ & 43 & Entretenimento & $\mathrm{M}$ & Marketing & Coordenadora de Inteligencia de Marketing & Comunicação Social_Publicidade \\
\hline 18 & $\mathrm{~F}$ & 37 & Comunicação e Design & $\mathrm{P}$ & Design & Gerente de Criação & Desenho Industrial (Design Grafico) \\
\hline 19 & $\mathrm{~F}$ & 32 & Mineração & G & Comunicação Corporativa & Gerente de Comunicação Interna & Comunicação Social_Jornalismo \\
\hline 20 & $\mathrm{~F}$ & 31 & Comunicação e Design & $\mathrm{P}$ & Comunicação Corporativa & Gerente de Planejamento e Atendimento & Comunicação Social_Jornalismo \\
\hline
\end{tabular}

Tabela 1 - Perfil dos entrevistados

\subsection{7}

\section{Coleta dos dados e as entrevistas}

A coleta de dados foi realizada no período de 02 de setembro e 22 de outubro de 2014 por meio de 20 entrevistas interpessoais (presenciais), com tempo médio de duração de 45 minutos, semiestruturadas, com gestores e profissionais sêniores de 10 organizações, sendo registradas através de gravação em áudio e posteriormente transcritas. Caso houvesse alguma restrição de cronograma para a realização presencial das entrevistas, algumas poderiam ser realizadas por Skype, o que não ocorreu.

No processo de coleta de dados, uma característica é o fato do "entrevistado refletir sobre sua experiência em um estado de "meta-consciência", ou seja, estar consciente de sua consciência sobre algo" (MARTON e BOOTH, 1997, p. 129) e, para isto, o contexto da conversa é pré-estabelecido, restrito ao objeto de pesquisa e deve ser o mesmo para todos os entrevistados (CHERMAN, 2013). Além disto, 
a autora, destaca a importância do entrevistador não introduzir novos materiais e temas que não façam parte da estrutura definida da entrevista.

A partir das gravações, as entrevistas foram transcritas por um profissional contratado totalizando em torno de 160 páginas e, em seguida, revisadas pela pesquisadora que checou cada uma das transcrições versus as gravações de áudios editando pontuação e ritmo do texto para que o sentido fosse fidedigno ao que os entrevistados exteriozaram.

Foram consultados conteúdos digitais disponibilizado na rede sobre as organizações entrevistadas tais como posicionamento, produtos e serviços oferecidos, porte e mercados de atuação para complementar dados levantados nas entrevistas.

\subsection{8}

\section{Análise e interpretação dos dados}

O método Fenomenográfico requer que a interpretação dos dados considere os conceitos de "Como" e "O que" em relação ao fenômeno, como mencionado o item 3.2.2.

Segundo Marton e Booth (1997), o pesquisador é um aprendiz no Método Fenomenográfico, buscando o significado e a estrutura de seu fenômeno (o como as pessoas experimentam o fenômeno de pesquisa em questão). A principal tarefa do pesquisador e aprendiz é discernir entre o que é a estrutura primária do fenômeno e o que é o significado atribuído por si mesmo.

Durante o processo das entrevistas, e posteriormente, a partir da leitura de suas transcrições e de todo material coletado, os dados foram organizados e sumarizados com vistas a construir categorias que reúnam dados relacionados. Inicialmente foram estabelecidas sete categorias que foram sendo agrupadas até as três categorias de descrição apresentada na presente análise de pesquisa.

Esse agrupamento busca mapear as percepções e experiências acerca de compartilhamento de competências (saberes e saberes-fazer) presentes em rotinas/processos inovativos, gerando categorias que se relacionem com os temas afins: Gestão da Inovação, Competências Coletivas e Rotinas Organizacionais.

A análise buscou evidenciar as relações existentes entre o fenômeno estudado e estes temas, alinhando o "Como" e "O que" da metodologia 
fenomenográfica às variáveis Compartilhar Competência e Busca de Inovação. Além disto, também foram analisados outros fatores relacionados ao fenômeno e apresentados pelos participantes. 


\section{4}

\section{Análise e interpretação dos dados}

\section{1}

As concepções dos indivíduos em relação ao compartilhamento de competência para a busca de soluções de problemas

O presente capítulo apresenta a análise dos dados que foram coletados por meio de entrevistas. As categorias aqui apresentadas emergiram do que foi expresso nas entrevistas acerca do que os indivíduos percebem e experimentam sobre o fenômeno de compartilhamento de competências para buscar soluções inovadoras. Estas categorias tentam organizar os achados sobre o fenômeno a partir do que os entrevistados exteriorizaram, sem pretender definir o fenômeno, mas apresentar como ele pode ser concebido quando vivenciado por indivíduos que compõe um grupo de trabalho em busca de soluções no contexto de uma organização.

\subsection{1 Compartilhamento de Competências nas Rotinas de Inovação como Criação de Competências Coletivas}

Esta categoria é fundamentada no desenvolvimento de competências coletivas durante o processo de busca de soluções inovadoras, que vai além da soma de competências individuais. A dinâmica de compartilhamento de competências, sejam conhecimentos, habildades ou atitudes, contribui no nível da competência individual considerando o contexto da equipe: os indivíduos desenvolvem a capacidade de trabalhar melhor quando fazem parte de determinado grupo. (COLIN e GRASSER, 2011). Ainda segundo os autores, "esta manifestação, que pode ser chamada de competência coletiva, se dá por processos de aprendizagem, de busca de soluções, de compartilhamento de pontos de vistas, de conversão de saberes tácitos e explícitos, ou ainda de transmissão de rotinas" (COLIN e GRASSER, 2011, p. 94). 
Para os participantes deste estudo, pertencentes a esta categoria, a troca de competências, aptidões, conhecimento e visões para a busca de soluções de problemas é percebido como um processo de aprendizado que ocorre durante a realização de atividades e de práticas individuais e conjuntas necessárias para a construção de novas soluções. O compartilhamento dos saberes e saberes-fazer pode aumentar a competência dos indivíduos e das equipes, sendo experimentado como um fenômeno que fomenta a aprendizagem, vivenciado de forma dinâmica e orgânica, e percebido como capaz de fornecer novos conhecimentos individual e coletivamente, promover a transformação de ideias e ampliar as possibilidades de soluções inovadoras:

"[compartilhar competência é] ... o essencial, é uma forma que você tem de conseguir os objetivos de maneira mais fácil, mais rápida, mais assertiva. Você trabalhando com uma equipe multifuncional cada um sabe bem uma área, você fica mais tranquilo e dá mais tranquilidade para a equipe. $\mathrm{O}$ mais importante e você poder contar com essa competência, mas também fazer ela rodar que é uma coisa que tentamos fazer muito. [...] Rodar o conhecimento, fazer com que as pessoas que não tenham apenas uma competência, por que tem algumas competências que não dá para passar é mais difícil de você passar esse aprendizado, mais alguma você consegue ir passando aos poucos para que a pessoa aprenda e aos poucos vai trocando essas experiências. $\mathrm{O}$ importante é você saber que alguns sabem coisas e os outros não e estas competências podem ser trocadas. Por que se ficar sempre com as mesmas competências fica uma coisa muito dura e tem que ser uma coisa mais flexível na estrutura." (Entrevistado 1).

Um dos contextos onde a competência coletiva está inserida é o da aprendizagem coletiva que "ocorre pela mudança de aprendizagem para a criação de um novo saber" (MICHAUX, 2005, apud SILVA, 2012, p. 6). A percepção dos participantes do estudo sobre o processo de mudança e evolução do conhecimento dos indivíduos inseridos um grupo de trabalho é descrita como um movimento de aprendizado contínuo: “a modificação do que está sendo desenvolvido de acordo com as reais dificuldades de realização apresentadas pelo outro, vai gerando um aprendizado para o futuro. " (Entrevistada 11) e a dinâmica de troca e acúmulo de novos saberes e de saberes-fazer entre os indivíduos é vivenciada em um contexto informal de construção conjunta do conhecimento. Neste contexto nasce um saber coletivo que evolui a cada processo de reunião de competências individuais em grupos de trabalhos para buscarem soluções de problemas: "Compartilhar gera mais saber e fazer." (Entrevistada 18).

Também é expresso pelos entrevistados que a discussão sobre o problema, em um grupo onde considera-se as diferentes visões, opiniões e conhecimentos 
dos participantes, promove o "exercício de buscar relações e analogias entre os diferentes olhares para trazer uma outra, ou nova, forma de solução de problema" (Entrevistado 13), o que gera uma co-dependência entre indivíduos de uma mesma área, de áreas diferentes e, eventualmente, de competências externas à organização. Esta agregação de profissionais intra e interdepartamentais ocorre mais organicamente nas atividades cotidianas de trabalho e, mais processualmente - ainda que pouco percebida como formal-, no desenvolvimento de projetos com objetivos e período de realização definidos, quando é mais comum a participação de profissionais externos a organização. A integração de diferentes profissionais, trazendo diversidade de experiências, habilidades e saberes permite o intercâmbio de conhecimentos técnicos, teóricos e práticos: “a participação de pessoas diferentes, de áreas diferentes aumenta o conhecimento do todo e também aumenta a competência do grupo" (Entrevistada 4).

A percepção do fenômeno acerca da co-dependência dos indivíduos na realização de rotinas de trabalho em grupo remete ao que Feldman e Pentland (2003) usam como metáfora para o fenômeno das ações interdependentes: "Como dançarinos, os participantes das rotinas organizacionais devem ajustar-se às ações de cada outro participante" (FELDMAN e PENTLAND, 2003, p. 104, apud FELDMAN e RAFAELI, 2002). Esta metáfora traduz de certa forma, a importância mencionada nas entrevistas quanto ao ambiente de trabalho ser harmônico e colaborativo para uma equipe que encara desafios comuns: "traz conhecimentos abrangentes e necessários de outras áreas, e quanto mais colaboração, mais criação e inovação" (Entrevistada 11).

Quando Zarifian (2012) discorre sobre as mudanças na organização do trabalho, citando as organizações que funcionam em rede e/ou por projetos, também apresenta a relação existente entre estas formas de organizar as equipes e a suas competências. Para o autor, tanto em redes (equipes interdepartamentais) ou por projetos (equipes intradepartamentais), “a competência é assumida por um coletivo, mas depende de cada pessoa individualmente". O trabalho da equipe traz um referencial para a ação de cada participante e o sucesso deste trabalho conjunto depende da "competência ativa de cada um" dentro do grupo que converge as competências individuais (ZARIFIAN, 2012, p. 63). Os entrevistados sempre que se referem ao sucesso do trabalho em equipe, afirmam que o trabalho conjunto é o responsável pelo resultado encontrado, uma vez que a integração de pessoas, e 
seus saberes, é o que permite que a solução seja alcançada, parecendo que falam de um saber coletivo para resolver um problema.

Quando solicitado a apontarem características individuais daqueles que formam estes grupos integrados, o "saber aprender" é uma característica individual destacada pelos participantes e também uma das competências individuais que Le Bortef (2003) considera importante para a construção do saber coletivo do grupo. A capacidade de interagir, de reconhecer e entender a competência dos outros indivíduos do grupo de trabalho, como também o interesse em aprender com eles são outras características individuais percebidas pelos participantes como importantes quando o compartilhamento de competências em rotinas de inovação é vivenciado como uma forma de aprender coletivamente, gerando novos saberes e saberes-fazer individuais e coletivos.

Para Le Bortef (2003), na perspectiva da competência coletiva a correlação de vários saberes e saberes-fazer estrutura uma "rede de competências" que promove a imbricação de inteligências onde a competência de cada um enriquece a rede e a competência gerada no coletivo pode ser mobilizada por cada participante da rede ou grupo. No relato dos entrevistados é evidenciado que a fusão dos saberes cria a competência coletiva do grupo e esse fenômeno ocorre durante o processo da busca conjunta de novos conhecimentos, quando os participantes ensinam e exercitam novos olhares sobre o problema, para que aprimorem suas atuações nos contextos individual e coletivo:

"Acho que quando de fato pesquisamos e mergulhamos no assunto podemos contribuir com o outro e eles viram este valor ao perceber esta integração e viram que faz sentido. [...] um compartilhar competências de forma clara para mim" (Entrevistada 10).

Le Bortef (2003) refere-se ainda a estas novas combinações no contexto dos grupos de trabalho como a capacidade "de criar e manter boas "sinapses" destas redes híbridas de competências. A aprendizagem coletiva não é substituível” (LE BORTEF, 2003, p. 234) e esta percepção é transmitida na fala de uma entrevistada:

"Compartilhar competências é poder trabalhar com muitas pessoas que são boas em algumas coisas para um bem maior. Juntar vários conhecimentos em prol de uma coisa que será melhor se todos colaborarem um pouco. No grupo multifuncional que mencionei antes, estes perfis vão depender do projeto, do que você está buscando. Eu acho que cada grupo multifuncional vai ser variável, mutável, evolutivo. E eu estou falando o que eu experimento. O que eu vivo" (Entrevistada 6). 
Na dimensão da Dinâmica das Rotinas Organizacionais, observa-se que os participantes mencionam que as práticas pré-estabelecidas são pouco frequentes e sinalizam que sua formalização ou normatização seria fator facilitador para o compartilhamento de competências. Nas entrevistas, é frequente a percepção de que deveria haver normas, métodos e/ou rotinas formalizadas para serem utilizadas e obedecidas quando os grupos se reuniam oficialmente para compartilhar seus saberes, parecendo que os participantes entendem que a existência de rotinas formais estimula e promove o fenômeno de compartilhamento de competências. Vale observar também que o contexto de informalidade e organicidade no qual o fenômeno de compartilhar competências ocorre, traz aparentemente um certo desconforto e/ou insegurança por parte dos entrevistados.

“... tem um lado formal sim, temos conseguido que esse processo seja formal. [...] trazemos o tema para a reunião, fazemos a pergunta e todos pensam juntos e começa a ação: esse é o lado formal dele, mas as melhores ideias acabam acontecendo de uma maneira natural. Eu acho que o que deveria se fazer, não somente para a minha área mas para a [empresa] de uma forma geral, seria criar uns rituais" (Entrevistada 16).

As rotinas organizacionais coordenam as ações coletivas, sistematizando os encontros e integração de grupos. Assim, além de promover a sinergia entre os indivíduos, as rotinas constituem a base dos saberes apreendidos e memorizados no nível coletivo (RETOUR et al., 2001). Os entrevistados com frequência aspiram pela institucionalização de rotinas que promovam a integração dos profissionais para que o compartilhamento de conhecimento ocorra mais frequente e formalmente no dia a dia de trabalho: “[...] é nas atividades diárias de trabalho que cada um traz o seu saber e saber-fazer" (entrevistada 4), que geram "um processo de descoberta e construção de novos conhecimentos" (entrevistado 10) durante a busca conjunta da melhor solução dos problemas.

Neste contexto do compartilhamento de conhecimento, pelo seu papel de transferir e promover a evolução de saberes e saberes-fazer dentro das organizações, as rotinas funcionam também como armazenadoras de antigos e novos conhecimentos e capacidades que constituem as competências coletivas (FELDMAN e PENTLAND, 2003; RETOUR et al., 2001; PARMIGIANi e HOWARD-GRENVILLE, 2011). A percepção da entrevistada 18 pode traduzir a 
relação das rotinas de inovação com o compartilhamento de conhecimento gerando novas possibilidades de soluções:

“[...] tem-se a noção de que as coisas são mais soltas do que de fato são. E o que entendemos dentro de um desenvolvimento de trabalho de inovação é um momento em que a troca precisa ser guiada, que o compartilhamento das competências vira em si uma ferramenta e não uma forma de se fazer" (Entrevistada 18).

O papel da liderança é mencionado como fundamental para estimular e respaldar a utilização e a formalização das rotinas que promovem a interação de equipes que buscam soluções de problemas:

"A motivação dessa equipe é muito importante, você mantém a união, a troca de informação e a busca pelo novo sempre. [...] a importância de um líder que seja motivador e que incentive a equipe a fazer aquilo é extremamente importante para que tudo aconteça" (Entrevistada 4).

Para Rerup e Feldman (2011) o papel do líder é heroico nesta dinâmica de utilização e atualização das rotinas de grupos de trabalho, pelas frequentes e ininterruptas discussões, consensos, tentativas e erros dos indivíduos que buscam novas possibilidades de aprendizados e realizações. Neste contexto de debate e negociações, os participantes da pesquisa consideram que o erro faz parte do processo e ele deve ser aceito por todo o grupo, e respaldado pela liderança, como uma fonte importante de geração de conhecimento para os envolvidos e para o próprio grupo e também como uma forma de mudar a práticas exercidas para buscar soluções.

O aprendizado por meio da tentativa e erro pode trazer evoluções na perspectiva ostensiva das rotinas e, consequentemente, gerar mudanças nas estruturas esquemáticas do grupo e da organização (RERUP e FELDMAN, 2011), como também contribuir para a construção contínua da competência coletiva que se exerce na realização das práticas conjuntas dos indivíduos.

$\mathrm{Na}$ busca de soluções, este estudo revela que a dimensão dos processos inovadores é vislumbrada quando, além da oportunidade de aprendizado, o fenômeno estudado permite que o indivíduo passe a "conhecer outras visões, outros modos de pensar" (Entrevistado 3) e, a partir do momento em que se considera o que é colocado por "aqueles que têm outra forma de ver o problema, pode surgir o novo" (Entrevistado 13). A diversidade de olhares e interpretações compartilhadas não resulta em justaposição de competências individuais, mas sim em um ponto de partida de um processo de fusão destas competências que se 
renova para cada grupo (COLLIN e GRASSER, 2011). E, de certa forma, assim o fenômeno é descrito por um entrevistado que declara que o rodízio de profissionais "dentro do departamento é bom para refrescar e aprender outras formas de fazer o trabalho em conjunto". (Entrevistado 7).

Quando uma equipe está reunida para o desenvolvimento de uma atividade ou projeto ocorre o compartilhamento de conhecimentos, conforme bastante mencionado até aqui, dentro de um contexto de ordem social: indivíduos diferentes que precisam ir em uma direção acordadamente comum para encontrar soluções. Os participantes da pesquisa reconhecem a importância desta diversidade, como também a fundamental necessidade de haver harmonia nos direcionamentos dos caminhos que o grupo irá tomar. A diversidade do grupo traz o acesso a diferentes perspectivas, informações e opiniões o que é positivamente relacionado às atuações de equipes que buscam soluções inovadoras. As divergências são produtivas trazendo novos conhecimento e entendimento, porém a convergência também deve estar presente para que haja a aceitação e a utilização dos saberes e saberes-fazer dos outros membros do grupo.

Paletz e Schunn (2009) elaboraram um modelo sócio-cognitivo que apresenta aspectos convergentes e divergentes, que integrados, direcionam para diferentes caminhos a serem percorridos por cada grupo de trabalho envolvido em soluções inovadoras. Os autores ressaltam que a integração sócio-cognitiva do grupo não significa que um se tornará um especialista em cada um dos diferentes domínios de conhecimento, mas vai adquirir o conhecimento necessário para facilitar o trabalho do time na busca da inovação. O presente estudo apresenta a percepção dos participantes de que a interação social e cognitiva de um grupo de trabalho promove reflexões individuais e coletivas que geram novas aprendizados, novos saberes e novos entendimentos para a equipe envolvida no processo - uma competência coletiva, que podem vir a ser o alicerce para a construção do novo:

"Você tem um série de problemas para os quais você não tem uma literatura para resolvê-los. Como você vai resolver sem a "jurisprudência"? Então o máximo do que você puder conversar com as pessoas mesmo que não tem nada a ver com aquilo... e vem o novo. O processo do novo vem de você desconstruir o velho" (Entrevistado 13).

Desta forma, quando um grupo que se reúne para compartilhar suas competências individuais, organicamente promove a interação dos saberes de cada um pertinentes às análises, questionamentos e reflexões acerca do problema em 
questão. Com disponibilidade para a busca conjunta, o grupo começa a funcionar coletivamente, percorrendo rotinas formais e informais, em uma dinâmica de divergir e convergir saberes e saberes-fazer até que surja uma competência coletiva do grupo que irá viabilizar a formatação de uma solução inovadora.

\subsection{2}

\section{Compartilhamento de Competências nas Rotinas de Inovação como Transformação do Fazer}

Nesta categoria, é analisado o impacto da interação dos saberes e saberesfazer dos indivíduos de um grupo que realizam rotinas e práticas durante o processo de busca de solução inovadora de problemas, observando se este compartilhamento - que gera novos conhecimentos, segundo os participantes também pode gerar novas formas de se observar, analisar, entender e solucionar os problemas. Enquanto a conceituação do fenômeno apresentada anteriormente aborda o compartilhamento de competências nas rotinas de inovação como um ambiente propício para o aprendizado, esta categoria apresenta o fenômeno como um potencializador de mudanças na forma de realizar tarefas, práticas e ações: tanto as que já são feitas como aquelas que serão novas, decorrente desta transformação do fazer. Nesta perspectiva, Crainer e Dearlove (2014) citam que Julian Birkinshaw e Gary Hamel "focaram na importância da gestão da inovação, a capacidade da empresa de realizar mudanças fundamentais em sua própria forma de trabalhar." (CRAINER e DEARLOVE, 2014, p.97).

Neste estudo, com relativa frequência, os entrevistados referem-se aos resultados que consideram inovadores como aqueles em que a forma de realizar o trabalho que chegará à solução foi modificada. As rotinas de inovação para estes participantes são aquelas que provocam esta modificação do processo de fazer, para resultar em algo novo ou o próprio processo seja considerado o novo: "Considero que solução inovadora é sempre um processo de melhoria e ela é o processo." (Entrevistada 16). Para os entrevistados, essas rotinas, quando realizadas em um contexto de compartilhamento de competências, aumentam as possibilidades de evolução, melhoria e/ou diferenciação destes caminhos que levam à solução de problemas:

"Cada profissional tem que saber um pouco de cada coisa para ser mais completo. Se você souber um pouquinho de cada área, você vai poder saber de 
assuntos diferentes, e cada uma vai ter uma perspectiva que vai ter uma ideia, uma sacada, uma forma de fazer diferente" (Entrevistado 1).

Quando os participantes descrevem o processo de busca de uma nova forma de fazer, a participação de integrantes com perfis diferentes entre si recebe significativa importância. A multidisciplinaridade é, para os entrevistados, fator de sucesso para a busca de solução inovadora. Observa-se que esta diversidade de saberes e saberes-fazer é percebida como uma das principais características que promove o enriquecimento do processo por estimular naturalmente o compartilhamento de conhecimentos e habilidades através de questionamentos mais frequentes, discussões mais amplas e diferenças significativas das opiniões individuais:

“... compartilhar competências com pessoas que são muito parecidas, que fazem as mesmas coisas, da mesma forma, acho que esse compartilhamento não é tão rico. Então na diferença é que isso fica mais forte. Então passa a observar o que o outro faz, o que ele tem para te oferecer e a partir disso que você consegue pensar diferente e a inovação tem esse caminho: como eu poderia fazer isso de forma diferente? O "fulano" faz isso dessa forma, talvez eu possa fazer assim ou então nós dois juntos, claro. [...] às vezes você tem uma ideia e outra pessoa diz que você poderia fazer de um jeito diferente e você acha muito bom. E você vai evoluindo junto com estas outras ideias e chega a algo mais inovador." (Entrevistada 15).

A diversidade das competências deve ser considerada na formação das redes de profissionais envolvidas para que não ocorra o estado de repetição, quando todos pensam e dizem as mesmas coisas. Esta percepção é corroborada por Le Bortef (2003): “A surpresa, o inesperado e, portanto, a criatividade não se manifesta mais. A cooperação supõe a diferença para funcionar de modo inovador, para criar valor agregado" (LE BORTEF, 2003, p. 250)

$\mathrm{Na}$ dimensão das competências individuais, que constroem a competência coletiva, Le Bortef (2003) sugere que o indivíduo deve integrar saberes múltiplos para encontrar a combinação necessária de suas competências a fim de atender as demandas de cada contexto. Essa mistura de múltiplos ingredientes presentes nas redes formadas por diversas competências fica evidente quando os participantes consideram as atitudes dos indivíduos são tão importantes como seus conhecimentos técnicos. Eles elencam as principais características individuais dos profissionais que compõe as redes de cooperação como comportamentais: 
disponibilidade em relação ao grupo, compromisso com o propósito comum, postura colaborativa e perseverança na busca de uma nova forma de fazer que seja melhor do que a conhecida; e como técnicas: alto nível de conhecimento específico e experiência prática.

Zarifian (2012) ressalta que dentro dos contextos organizacionais, a cooperação no trabalho tem assumido importante destaque, uma vez que o intercâmbio de saberes, os confrontos de ideias e de soluções promovem envolvimentos subjetivos que se tornam cada vez mais necessários para a resolução de problemas complexos e interdependentes. Indo de encontro a esta observação do autor, emerge da narrativa dos participantes a percepção de que para haver condições de mudanças - transformações das formas de fazer -, os integrantes da equipe de trabalho devem estar dispostos a trabalhar cooperativamente e, para que essa cooperação ocorra, consideram fundamental que o grupo saiba promover conjuntamente um ambiente colaborativo e de integração dos conhecimentos e das experiências diversas:

"[...] o grupo deve ter complementaridade total, e você tem que entender quais são estas forças. [...] o grupo é diverso, mas os valores tem que ser alinhados e tem que ter o propósito do grupo, o que normalmente é: estamos juntos [...] os problemas e as diferenças existem, mas os valores são mais fortes." (Entrevistada 19).

Desta forma, a cooperação contínua entre os participantes do grupo visando sempre um objetivo comum é uma competência do âmbito coletivo que recebe destaque nas entrevistas e se estende aos profissionais externos à organização que, para os entrevistados, contribuem significativamente para se encontrar novas formas de fazer com sua experiência em outros ambientes e indústrias. O compartilhamento de saberes e saberes-fazer de integrantes externos à organização é visto, pelos entrevistados, como necessário em grande parte dos processos de busca de soluções, não somente cotidianos como também os de projetos multidisciplinares:

“[...] uma vez conceituada a proposta de solução, parto para o fornecedor para saber sobre a viabilidade da ideia: ele tem o "know-how. Depois também observando outra montagem (solução dele) vi que usava outro material e ele me explicou e chegamos a conclusão que valia a pena tentar." (Entrevistada 15). 
A este respeito, Le Bortef (2003) lembra que dentro do conceito de rede de competências, as competências externas à empresa devem ser consideradas como parte integrante do grupo de trabalho em rotinas de inovação. Em sua abordagem sobre a participação de integrantes externos - fornecedores, franqueados, clientes - o conceito de empresa-rede é apresentado e contextualizado como presente em alguns exemplos dos setores automobilístico e farmacêuticos.

Quando o fenômeno de compartilhar competências em rotinas de inovação é experimentado como a transformação do fazer, os entrevistados consideram que as rotinas e as práticas que levam à solução de problemas devem ser revisitadas sempre para que ocorra a inovação, para que ocorra a nova forma de fazer, que gera um resultado melhor e/ou diferenciado. Ou seja, a possibilidade de fazer algo novo está alicerçada na mudança da forma de fazer:

"[...] além dos resultados numéricos, têm os resultados de satisfação e vamos descobrir um novo jeito de fazer determinada coisa para ter estes resultados. A sensação de fluxo de trabalho de melhora, não só através do resultado numérico, mas também através do resultado processual." (Entrevistada 6).

Rotinas formais e informais fazem parte dos processos de busca de soluções inovadoras, sendo que os entrevistados avaliam a organicidade do processo como positiva, apesar de possuírem expectativas de que, se as rotinas fossem normatizadas, o processo ocorreria de forma mais fácil, mais frequente e mais disseminada. A informalidade, muitas vezes denominada nas entrevistas de "forma orgânica", gera certo desconforto por parte dos participantes da pesquisa. Porém, como percebem o fenômeno de compartilhar competências em rotinas de inovação como transformar o fazer, eles conseguem perceber que esta forma orgânica é a que viabiliza melhor essa transformação, o que não impede que se preocupem com a pouca normatização das rotinas de inovação.

Esta situação de desconforto, entre o que é formal e o que é informal nas práticas organizacionais, vai de encontro ao que Lam (2004) observa como necessário nos cenários competitivos: a diversidade de ambientes organizacionais construídos por atividades associadas às novas tecnologias promovem uma complexidade e incerteza na gestão de produtos e serviços, que somados à imprevisibilidade e heterogeneidade das práticas realizadas para atendê-la, fazem com que as empresas tenham estruturas mais adaptáveis e flexíveis. Esta tendência 
faz com que processos burocráticos deem lugar a formas mais orgânicas de realização. (LAM, 2004).

Considerando esta perspectiva menos rígida de observar as rotinas, o erro pode ser considerado um fator importante para o desenvolvimento de tal capacidade de mudança contínua. Rerup e Feldman (2011) em seus estudo relacionando rotinas e o processo de tentativa e erro, defendem que quando as rotinas já formalizadas e utilizadas em uma organização não atendem as expectativas esperadas, o evento resultante é um problema. O processo de tentativa e erro irá formatar uma nova rotina que quando bem sucedida irá substituir a anterior. Este contexto de valorizar o erro para que haja a transformação do fazer vai de encontro às experiências vividas pelos participantes da pesquisa, que expressam a importância da dinâmica de tentar e errar para perceberem exatamente em que ponto da análise, da interpretação e da prática a mudança deve ocorrer: “[...] o erro às vezes mostra que a tentativa não foi boa, mas era necessária para saber o que fazer em seguida." (Entrevistado 4).

Nesta categoria, o compartilhamento de competências nas rotinas de inovação é vivenciado pelos participantes do estudo como capazes de transformar a forma de realizar as tarefas, as práticas ou os processos produtivos. A transformação do fazer pode gerar uma modificação no resultado já conhecido, trazendo novos valores agregados aos produtos e aos serviços oferecidos pela organização. Segundo os participantes, o "novo fazer" possui caráter evolutivo, podendo ser considerado uma diferenciação em relação à solução existente: a perspectiva inovadora estará no fazer de outra forma, não trazendo necessariamente ao resultado final uma percepção de ser uma nova entrega, mas uma entrega melhor ou diferenciada em relação à anterior. Uma nova diferença. Para Zarifian (2003), “a reunião de competências humanas em torno de projetos descentralizados tem efeitos mobilizadores muito importantes e pode gerar novas fontes de valor", seja por permitirem a experimentação de novas formas de produzir, seja pela experimentação de uso dos recursos de forma flexíveis e não testados (ZARIFIAN, 2003, p. 99). Um exemplo enriquecedor para esta perspectiva do processo de inovação é dado pela Entrevistada 11: 
"A criatividade e a inovação são novas maneiras de ver as coisas que sempre existem, você tem que dar um novo olhar para as mesmas coisas que estão sempre voltando. Por exemplo, temos que fazer uma vitrine de natal, como vamos reinventar um natal em 2014, o natal existe desde 1800, sendo celebrado todo ano principalmente na minha área de mercado que é varejo? Temos que fazer isso sempre com um novo olhar. Sempre fazer aquilo de maneira diferente. [...] tem uma coisa de melhoria sim. Não nascem necessariamente do zero. Das mesmas coisas nascem coisas novas, por que senão você tem sempre que reinventar a roda e na verdade você está sempre fazendo de forma diferente, a mesma plataforma com outro olhar sempre, um olhar inovador, que leve em consideração o tempo que você vive. Outro exemplo, antigamente não existia tecnologia como iPad e hoje você pode colocar dentro de uma vitrine, utiliza mecanismos novos levando em consideração o tema que é antigo.” (Entrevistada 11)

Esta categoria pretende mostrar que o compartilhamento de competências, que emerge organicamente da interação das competências individuais, pode provocar a transformação do fazer a partir da dinâmica da construção da competência coletiva discutida na categoria anterior. Na busca de um resultado diferente, melhor ou totalmente novo, um conhecimento coletivo é gerado que fundamenta um modelo coletivo de fazer diferente: multidisciplinar, simultaneamente formal e informal, e alavancador de novas rotinas ou práticas que poderão ser incorporados pela gestão organizacional.

\subsection{3 \\ Compartilhamento de Competências nas Rotinas de Inovação como Construção de Padrão de Pensamento}

Esta categoria aborda o fenômeno de compartilhar competências nas rotinas de inovação como articulador de um modelo mental de observação, análise, raciocínio e reflexão que pode ser encontrado nas práticas coletivas em busca da solução de problemas. Para Le Bortef (2003), um dos componentes da competência coletiva é saber elaborar representações compartilhadas, quando há a convergência de referências individuais na direção de um referencial comum, criando um "espaço problema". Este referencial não é fornecido ao grupo, como também não é estável, mas é resultante da construção comum e evolutiva à medida que a equipe adquire experiências por meio de enfrentamento dos problemas, das ações realizadas e da pesquisa coletiva. Essa representação compartilhada, segundo o autor, formatam-se como "mapas cognitivos comuns", que representam “processos de pensamentos, modos de raciocínio, relações de 
causa e efeito, classificação e tipologia aos quais se referem os membros de uma equipe ou rede." (LE BORTEF, 2003, p. 235).

Desta forma, quando os participantes da pesquisa enfatizam que o exercício do compartilhamento de competências na busca de soluções inovadoras decorre de uma forma de trabalhar em grupo multidisciplinar: olhar, analisar e idealizar conjuntamente problemas e soluções, pode-se supor que exista nos grupos com representações comuns - e também diversas - um modelo de pensar coletivo, sobre os problemas novos ou já existentes, que permitirá a geração de novas interpretações, novas ideias, de novas possibilidades para encontrar soluções inovadoras.

Ainda na perspectiva da possibilidade de formatação de um padrão de pensamento para a busca de soluções inovadoras, vale observar que Retour e Krohmer (2011) citam dois processos de geração de competência coletiva descritos por Wittorski (1997): o primeiro no âmbito do compartilhamento de pensamento individual sobre o trabalho e a forma de vê-lo; e, o segundo correspondeu a elaboração de um pensamento coletivo novo, decorrentes de questionamento no grupo que levam a novas formas de ver e de tratar o trabalho. Assim, pode-se começar a inter-relacionar as categorias deste estudo considerando que, na busca de soluções, os grupos têm possibilidade de gerar competência coletiva e transformar a forma o fazer, acionando um padrão de pensamento para a inovação.

"É uma das melhores formas de se encontrar a soluções é quando você compartilha uma competência. É você encontrar outras competências. Se você senta e busca a solução sozinho você consegue. Principalmente se você for uma pessoa relativamente capaz e disposta. Agora se você troca e ouve outras visões e outras perspectivas daquele problema, acelera muito o processo porque você não só ouve coisas de fora, como é estimulado a pensar diferente do que você estava pensando. Pensar juntos. Pegar novos caminhos.” (Entrevistada 2)

“Eu não sei se é uma condição super especifica. Não necessariamente duas cabeças pensam melhor que uma, não necessariamente o grupo cria coisas maravilhosas, não acho isso mas acho que o ganho do ser humano é muito bom. E é isso que é muito louco por que se o ganho do ser humano for muito bom, aí sim este grupo começa a funcionar como uma pessoa só, ele começa a se ajudar e não há puxar para lados diferentes. É lógico que se tem reuniões, discussões, as pessoas começam a puxar para lados diferentes, é lógico que acontece isso também, agora acontece cada vez menos quando o lado que alguém está puxando tem uma explicação mais racional, acho que isso começa a facilitar: a chave mais legal para conseguir que todo mundo comece a pensar de uma forma parecida, não o resultado parecido, mas todos pensando "para lá", seja lá qual for o corpo que vai aparecer, 
mas é "para lá"... é que esse "lá" tem o argumento mais racional, a empresa quer chegar "lá" (Entrevistado 7)

Na dimensão das competências individuais, para os entrevistados que percebem um modelo de pensamento ativo no grupo que busca soluções inovadoras de problemas, as principais características dos indivíduos aderentes a este grupo são as capacidades de ouvir o outro, e de se fazer ouvir e de ter uma mente aberta capaz de considerar todas as possibilidades colocadas pelos integrantes do grupo. Esta disponibilidade dos indivíduos é uma postura considerada importante por muitos dos participantes do estudo, traduzindo a atitude necessária de contribuição sinérgica de cada um para com o grupo para que haja a interação e construção de uma forma consensual de interpretar, analisar e solucionar o problema.

A partir das características individuais e coletivas destacadas pelos entrevistados, a comunicação adquire importância na dinâmica de integração e interação de saberes e saberes-fazer da equipe. Indo de encontro com essa percepção dos participantes do estudo, Zarifian (2003) explica que a comunicação vai além da coordenação e disponibilização das informações: ela constrói as bases para entendimento recíproco e para o alinhamento das ações a serem realizadas. (ZARIFIAN, 2003; LE BORTEF, 2003). Das entrevistas do estudo emerge os relatos de experiências vividas dentro de um contexto diário de cooperação e ajuda mútua, que geram uma situação de dependência entre todos os integrantes do grupo que continuamente estrutura o pensamento integrado.

Uma vez estabelecida a interação e integração dos indivíduos de um grupo de trabalho, os questionamentos, as discussões e as elaboração de diferentes propostas ocorrem pela presença de um senso crítico, característica presente no modelo de pensamento do grupo. Os entrevistados percebem que opiniões divergentes enriquecem o processo de intercâmbio de saberes e saberes-fazer, para que as análises e as reflexões possibilitem que surjam soluções diferentes das normalmente esperadas. As ideais e os conceitos que fundamentam a solução buscada, nascem do resultado deste processo em um contexto de senso comum:

" O compartilhar é compartilhar ideias, conhecimentos, ter visões diferentes, de conhecer essas outras visões, essas outras oportunidades, o modo de pensar. [...] É quando te faz refletir sobre uma coisa que é tão clara para você, então o óbvio 
onde você tomaria uma certa decisão e alguém chega para você e dá uma outra opinião que te faz pensar que realmente existem outros caminhos diferentes para resolver aquele problema, e que você não havia pensado. E então você começa a enxergar o problema diferente, entender de outras formas diferente. Tem o compartilhamento quando te faz pensar mesmo. [...] E sair do mesmo te faz pensar e é uma coisa que não é fácil, e você fazer isso sozinho é muito mais difícil, então você tem que ter um compartilhamento para que você consiga chegar a uma solução inovadora, ter uma nova ideia, pensar diferente. Para trazer coisa nova tem que ter o compartilhamento de competências porque tem que enxergar as coisas de forma diferente, tem que refletir, tem que pensar, tem que analisar, tem que trocar ideias, trocar conhecimentos para conseguir chegar a uma inovação." (Entrevistada 3)

Cientistas cognitivos de ciência e tecnologia têm discutido a diversidade de conhecimento nos grupos de trabalho como uma base mais ampla para o pensamento, onde modelos mentais compartilhados possam minimizar as lacunas da linguagem disciplinar. Esta diversidade traz pensamentos divergentes que ressaltam aspectos da criatividade: geração de muitas ideias e uma lista de possibilidades, enquanto que os pensamentos convergentes buscam encontrar um único resultado de alta qualidade e que é a resposta ideal para solução do problema. A maioria das atividades em grupo envolvem os dois tipos de pensamento e, em inovação, a implementação provoca que o resultado final venha dos pensamentos convergentes (PALETZ et al., 2010). Tal convivência de pensamentos divergentes e convergentes, apresentada pelo autor, fundamenta a vivência trazida pelos entrevistados de experimentar o compartilhamento das diferentes formas de pensar, tanto o problema como a solução, para se chegar a um resultado que atenda ao objetivo comum: de caráter inovador.

"Uma solução para você é considerada inovadora sem ser aquelas que surgem como mágica, né? E não é assim. É com muito suor. Acontece quando ela tem como base essa visão de vários pontos de vistas diferentes. O resultado dessas diferentes visões acaba gerando um resultado que é diferente do original. Do que é o resultado esperado. E nasce com o grupo compartilhando, concordando." (Entrevistado 5)

Para os participantes da pesquisa, a construção de um modelo de pensamento durante o compartilhamento de competências conta com a participação de indivíduos de outras empresas - parceiros e fornecedores, sendo percebida como uma importante contribuição para o pensamento do grupo 
transcorra de forma mais ampliada, uma vez que trazem outras realidades já vivenciadas:

“A competência externa não necessariamente é uma empresa só, porque tem diferenças: tem empresas muito ligadas a jovens, outras ligadas a comportamento em geral, outras focadas em pesquisa de campo mesmo, em análise de conteúdo.... então estamos em constantes processos de exercer novos olhares e elas buscam um outro entendimento.” (Entrevistada 12)

Enquanto que na categoria anterior, onde o compartilhamento de competências nas rotinas de inovação pode transformar o fazer, as percepções relatadas descrevem os processos realizados na busca de soluções de um grupo de trabalho, nesta categoria observa-se a valoração do aspecto mais performativo das rotinas: consiste em uma ação específica, realizada por um indivíduo específico em um momento e contexto específicos, uma vez que a atuação do indivíduo se dá como decorrência da forma de pensar do grupo, ou seja, é adaptada, improvisada, customizada para tal situação. $O$ conceito de improvisação, mencionado anteriormente na referência de Le Bortef (2003), aparece aqui com inerente a esta dinâmica descrita pelos participantes como informal, que se traduz em um grande repertório de possibilidades de ações e tarefas em cada grupo de trabalho que poderá ou não se repetir em contextos diferentes.

A corrente Prática que fundamenta o aspecto performativo das rotinas traz uma dimensão oposta ao entendimento de que a prática é relacionada às regras e às expectativas. Nesta abordagem, observa-se que na maioria das vezes, escolhese novos tipos de ações para realizar tarefas, decorrente da reflexão para dar sentido ao que se está fazendo, trazendo assim as peculiaridades individuais de cada um. (FELDMAN e PENTLAND, 2003). Desta forma, o aspecto performativo das rotinas, que possui características de improvisação, pode ser considerado um dos alicerces da forma orgânica (não formal) em que as rotinas de inovação ocorrem, na busca de soluções de problemas:

"Deveria ter reuniões agendadas com mais frequência para os debates entre as áreas. $\mathrm{Na}$ [departamento] até tem, de certa forma, essas reuniões semanais, mas estão fechadas às demandas da [departamento] e não estão ouvindo os palpites de fora para [departamento], o interdisciplinar deveria ter mais. Os profissionais acabam atropelados pela quantidade de coisas que tem para fazer todos os dias e que não conseguem ter um tempo dele mesmo pensar ou criar inovação. Talvez seja por isso que as grandes empresas criam um departamento de inovação em que 
os funcionários interdisciplinares são colocados lá para fazer única e exclusivamente isso, se não for assim fica muito difícil." (Entrevistada 14).

Os participantes relatam com frequência que seria importante uma maior existência de rotinas formais que estimulassem a prática da reflexão coletiva. Porém, mesmo que tais rotinas não sejam formalizadas em ambientes organizacionais, a prática de pensar coletivamente ocorre naturalmente pela necessidade já interiorizada dos participantes de compartilhar visões, interpretações, análises e sugestões. Os entrevistados atribuem um significativo valor à reflexão sobre outras opiniões e ideias para encontrem possibilidades diferentes das que as rotinas vigentes estimulam, além de considerarem que esta prática reflexiva deveria estar disseminada dentro da organização formal e informalmente. Essas vivências e experiências que emergem das entrevistas corroboram a associação que Tsoukas e Chia (2002) fazem entre regras e normas rígidas e uma menor adaptação às mudanças pela ausência de reflexão, conexão e improvisação no ambiente organizacional, o que pode conduzir a um formato de equilíbrio entre a formalidade e informalidade de determinadas práticas organizacionais.

"Você chegar a um resultado inovador, é você propor alguma coisa para chegar a um resultado melhor, de uma maneira diferente, talvez não convencional. Não no sentido de ser somente fora da caixa, mas não convencional: de um caminho não trilhado ainda. É tão mais fácil você pegar soluções que já tem um gabarito, aplicar aquele gabarito para repetir aquela forma, já é convencionalmente aprovado, todos já conhecem, todo mundo já entende que é a solução por que sempre fez assim, é tão mais fácil você pegar aquilo e ficar reaplicando, reaplicando, reaplicando. Isto não muda nada." (Entrevistada 9).

Percepções como essa surgiram algumas vezes nas entrevistas e podem ir de encontro ao conceito apresentado por Dionysiou e Tsoukas (2013) de que a realidade é um processo contínuo de possibilitar algo novo. Os entrevistados exteriorizam que a integração e interação de saberes e saberes-fazer, somados às diferentes visões, interpretações e análises, provocam além da evolução do entendimento individual sobre o problema, a construção de uma forma de pensar coletiva sobre ele. Essa percepção que emerge do campo caracteriza que as rotinas podem ser mudadas em decorrência da necessidade de improvisação para atender ao modo de pensar coletivo que busca novas formas de resolver um problema. 
O entendimento de inovação neste estudo foi frequentemente associado a um resultado de melhoria, de evolução em relação às entregas previamente conhecidas, resultante do processo de trabalho realizado pela equipe. Ainda que o conceito de inovação seja objeto de discussão, a tradicional distinção entre inovação incremental e inovação radical (CAGNAZZO, TATICCHI e BOTARELLI, 2008) parece ser o parâmetro de referência da maioria dos entrevistados. Emerge das entrevistas a percepção de que a construção de um novo processo pode ser considerada como a inovação ou o desenvolvimento de uma entrega de produto ou serviço, com alguma ou algumas características novas, faz com que este resultado seja percebido como inovador, não precisando ser uma solução totalmente original. Eis um depoimento a esse respeito:

“ [...] os aplicativos de táxi, não tem coisa melhor no mundo. É um processo velho, você está chamando um táxi, mas o meio de fazer isto melhorou e mudou. O Wase também: ele é inovador e evolui com mais inovação: agora você fala o endereço, sem ter que digitar." (Entrevistada 6).

O modelo mental coletivo de um grupo de trabalho que busca soluções inovadoras pode ser considerado como uma plataforma que viabiliza ao grupo encontrar novos caminhos, novos resultados, que tragam mudanças incrementais ou radicais aos produtos ou serviços de uma organização. Estudos de aprendizado organizacional e criação de conhecimento, relacionados à construção de competências, apontam a capacidade das organizações em pensarem e agirem coletivamente, e como o compartilhamento de um modelo mental ou esquema interpretativo pode afetar a adaptabilidade organizacional. (LAM, 2004). Assim, o padrão de pensamento de grupos de trabalho que buscam inovar em suas soluções parece funcionar dentro de uma perspectiva onde a mudança e a evolução de processos e resultados são considerados como inovação: "Ela [inovação] pode ser a melhoria, mas ela é original: esse pulo, essa melhoria é o original." (Entrevistada 19).

Esta categoria tenta tornar mais clara e visível a existência de um modelo construído organicamente por um grupo de trabalho a partir da aceitação e alinhamento de alguns parâmetros, mesmo que haja - e seja desejada - a divergência. Tais parâmetros parecem ser da ordem da liberdade individual de se colocar, da disponibilidade do grupo de ouvir, da flexibilidade de integrar 
possibilidades e ideias, da cooperação entre todos, da busca de integração de saberes para transformar o fazer na busca por inovação. Neste contexto, o grupo realiza as etapas necessárias para a construção da solução, exercitando um modelo comum de pensamento que suporta desde a liberdade até a cooperação, e principalmente viabilizar a identificação do novo.

A Tabela 2 apresenta o Espaço de Resultado para as concepções que emergiram da pesquisa sobre o fenômeno de Compartilhamento de Competências para a busca de soluções inovadoras, sintetizando as dimensões das três categorias descritivas apresentadas e discutidas anteriormente. 
Compartilhamento de Competência em Rotinas de Inovação

(Compartilhar competências para busca de soluções inovadoras)

\begin{tabular}{|c|c|c|c|}
\hline $\begin{array}{c}\text { Percepção/ } \\
\text { Concepção }\end{array}$ & $\begin{array}{l}\text { Criação de Competência Coletiva } \\
\text { (um modelo de integração) } \\
\text { (a forma de aprender coletivamente) }\end{array}$ & $\begin{array}{l}\text { Transformação do Fazer } \\
\text { (um modelo de mudança) } \\
\text { (a forma de realizar coletivamente) }\end{array}$ & $\begin{array}{l}\text { Construção de Padrão de Pensamento } \\
\text { (um modelo de inovação) } \\
\text { (a forma de pensar coletivamente) }\end{array}$ \\
\hline $\begin{array}{l}\text { Conceito de } \\
\text { Compartilhamento } \\
\text { de Competência }\end{array}$ & $\begin{array}{l}\text { Intercâmbio de saberes e saberes-fazer: } \\
\text { aprendizado para os indivíduos e para o grupo } \\
\text { de indivíduos envolvidos na solução do } \\
\text { problema, aumentando suas competências. } \\
\text { Processo informal de construção conjunta de } \\
\text { conhecimento. } \\
\text { Geração de co-dependência entre equipes intra } \\
\text { e interdepartamentais geradas em cada solução } \\
\text { de problema ou desenvolvimento de projeto. }\end{array}$ & $\begin{array}{l}\text { Interação de visões, de conhecimentos, de } \\
\text { saberes-fazer para evoluir, melhorar e } \\
\text { diferenciar os caminhos que levam a solução de } \\
\text { um problema. } \\
\text { O conhecimento formal multidisciplinar do } \\
\text { grupo é valorado por promover } \\
\text { questionamento, discussão e alinhamento de } \\
\text { opiniões diferentes promovendo novas } \\
\text { possibilidades de realização no processo de } \\
\text { busca da solução do problema. }\end{array}$ & $\begin{array}{l}\text { Criação de modelo de observar (olhar) analisar } \\
\text { e idealizar - individual e coletivamente - que } \\
\text { promove o compartilhamento de um padrão de } \\
\text { pensamento inovador: busca soluções } \\
\text { totalmente novas, mesmo que para um } \\
\text { problema já existente ou recorrente. } \\
\text { Modelo mental pode ser considerado com uma } \\
\text { plataforma que viabiliza ao grupo encontrar } \\
\text { novos caminhos, novos resultados que tragam } \\
\text { mudança incrementais ou radicais aos produtos } \\
\text { e serviços da organização. }\end{array}$ \\
\hline $\begin{array}{l}\text { Perspectiva da } \\
\text { Competência } \\
\text { Individual } \\
\text { (dos saberes e } \\
\text { saberes-fazer } \\
\text { individuais) }\end{array}$ & $\begin{array}{l}\text { Capacidade de interagir para aprender. } \\
\text { Capacidade de reconhecer e entender a } \\
\text { competência do outro. } \\
\text { Curiosidade/interesse para aprender com o } \\
\text { outro. }\end{array}$ & $\begin{array}{l}\text { Ser e estar disponível. } \\
\text { Alto nível de competência: conhecimentos e } \\
\text { capacidade de realizar, de fazer acontecer. } \\
\text { Ser perseverante, não acomodado. } \\
\text { Ser comprometido. } \\
\text { Ser colaborativo. } \\
\text { Ser criativo. }\end{array}$ & $\begin{array}{l}\text { Ser e estar disponível. } \\
\text { Saber ouvir. } \\
\text { Saber se fazer ouvir. } \\
\text { Ser mente aberta, flexível, para considerar todas } \\
\text { as possibilidades colocadas pelo grupo. } \\
\text { Ser engajado, com paixão... } \\
\text { Ser criativo. } \\
\text { Ser ousado, desapegado. }\end{array}$ \\
\hline $\begin{array}{l}\text { Perspectiva da } \\
\text { Competência } \\
\text { Coletiva } \\
\text { (dos saberes e } \\
\text { saberes-fazer } \\
\text { coletivos) }\end{array}$ & $\begin{array}{l}\text { Saber provocar conjunta e harmonicamente a } \\
\text { busca de novos conhecimentos, ensinando e } \\
\text { exercitando novos olhares sobre o problema } \\
\text { para que todos cresçam/evoluam no exercício } \\
\text { de seus diferentes papéis dentro do grupo de } \\
\text { indivíduos. }\end{array}$ & $\begin{array}{l}\text { Saber promover um ambiente colaborativo e de } \\
\text { integração/fusão dos conhecimentos, das } \\
\text { habilidades e das experiências de um grupo } \\
\text { multidisciplinar para que seja possível exercer } \\
\text { um novo saber-fazer coletivo. } \\
\text { Promover a busca de competências externas ao } \\
\text { grupo, quando necessário: outras áreas, } \\
\text { departamentos ou organizações. }\end{array}$ & $\begin{array}{l}\text { Saber promover um ambiente com senso crítico } \\
\text { que promova a elaboração, a discussão e o } \\
\text { entendimento sobre as visões individuais e } \\
\text { coletivas de um grupo composto por uma } \\
\text { diversidade de competências para gerar } \\
\text { soluções de senso comum. } \\
\text { Participação de competência externa mais } \\
\text { frequente e demandada desde o início da busca } \\
\text { de solução do problema. }\end{array}$ \\
\hline
\end{tabular}




\begin{tabular}{|c|c|c|c|}
\hline $\begin{array}{l}\text { Dinâmica das } \\
\text { Rotinas } \\
\text { Organizacionais }\end{array}$ & $\begin{array}{l}\text { É pressuposto que promovam formal ou } \\
\text { informalmente a interação dos saberes e } \\
\text { saberes-fazer individuais na realização das } \\
\text { atividades pré-estabelecidas ou das atividades } \\
\text { de novos problemas ou projetos. } \\
\text { A liderança suporta e estimula a formalização } \\
\text { das práticas interativas, além de suportar e } \\
\text { viabilizar as práticas e processos. } \\
\text { O erro é considerado parte do aprendizado e } \\
\text { deve ser aceito por todo o grupo. }\end{array}$ & $\begin{array}{l}\text { Os aspectos funcional e prático das rotinas } \\
\text { recebem maior atenção nas análises, } \\
\text { interpretações e diagnósticos da busca de } \\
\text { solução de problemas: os processos "de fazer", } \\
\text { formais e informais, são o foco central das } \\
\text { mudanças e das diferenciações buscadas pelos } \\
\text { indivíduos e grupos de indivíduos na nova } \\
\text { solução. } \\
\text { O erro é valorizado e considerado necessário } \\
\text { para que haja a transformação do fazer. }\end{array}$ & $\begin{array}{l}\text { Os processos formais promovem a integração } \\
\text { do grupo de indiví́duos, enquanto as práticas } \\
\text { informais promovem a interação orgânica de } \\
\text { suas contribuições, sendo necessário a curto } \\
\text { prazo uma maior formalização do processo } \\
\text { (área responsável). } \\
\text { Dinâmica de reconhecido valor, com } \\
\text { contribuição ainda maior se realizada de modo } \\
\text { contínuo. } \\
\text { As rotinas podem ser mudadas em decorrência } \\
\text { da necessidade de improvisação para atender ao } \\
\text { modo de pensar coletioo que buscas novas } \\
\text { formas de resolver o problema. } \\
\text { O erro é uma das possibilidades do modelo } \\
\text { mental. }\end{array}$ \\
\hline $\begin{array}{l}\text { Contexto dos } \\
\text { Processos } \\
\text { Inovadores }\end{array}$ & 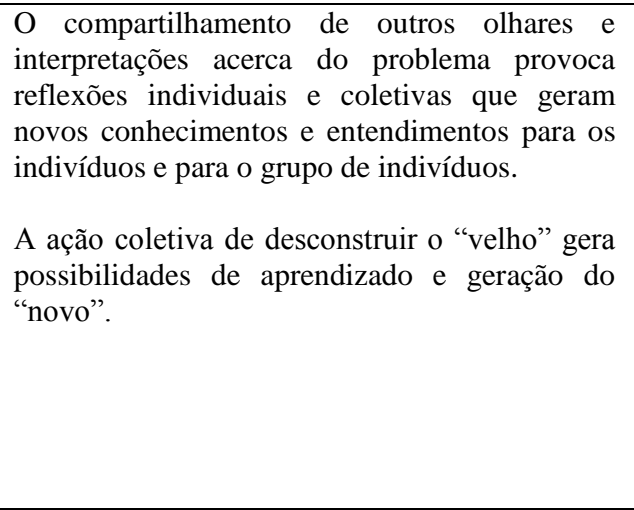 & $\begin{array}{l}\text { Uma nova forma "de fazer" pode modificar } \\
\text { aquilo que já existe e ser considerado inovador. } \\
\text { De caráter evolutivo e trazendo melhoria do } \\
\text { processo "de fazer", o resultado é diferente do } \\
\text { original, pode ser surpreendente, e não é uma } \\
\text { percebido como uma invenção (solução } \\
\text { totalmente nova). } \\
\text { Uma nova diferença: o novo pode ser a } \\
\text { mudança que trouxe a diferença e, } \\
\text { consequentemente, novos valores agregados ao } \\
\text { produtos e serviços oferecidos pela } \\
\text { organização. }\end{array}$ & $\begin{array}{l}\text { O processo entrega percepção de algo inovador: } \\
\text { um resultado diferente da solução existente ou } \\
\text { do contexto em que está inserida, decorrente do } \\
\text { saber coletivo, da transformação do fazer e da } \\
\text { reflexão compartilhada. } \\
\text { O caráter evolutivo é associado à nova solução } \\
\text { de um problema continuamente existente que, } \\
\text { neste contexto, foi analisado a partir de uma } \\
\text { perspectiva diferente. }\end{array}$ \\
\hline Perfis X Conceitos & $1,9,10$ & $2,6,7,8,9,12,14,17,19,20$ & $3,11,15,16$ \\
\hline $\begin{array}{l}\text { Perfis X Conceitos } \\
\text { em transito }\end{array}$ & & $13^{4}$ & 18 \\
\hline
\end{tabular}

Tabela 2 - Espaço de Resultado para as concepções sobre Compartilhamento de Competências em Rotinas de Inovação 


\section{2 \\ A Correlação das Concepções dos Indivíduos em relação ao compartilhamento de competência para a busca de soluções de problemas}

As concepções sobre o fenômeno de Compartilhamento de Competência nas Rotinas de Inovação que emergiram do campo realizado para este estudo, apresentadas e sumarizadas nos tópicos 4.1.1 a 4.1.3, se organizam hierarquicamente de forma crescente e inclusiva.

A primeira concepção, Criação de Competência Coletiva, parece estar presente na maioria dos grupos de trabalho que buscam soluções inovadoras. Para grande parte dos participantes o processo de compartilhar saberes e saberes-fazer com os indivíduos de um grupo de trabalho ao qual pertencem proporciona um aprendizado individual, mas sempre que descrito, é contextualizado em ações do grupo de trabalho. O aprendizado parece ser interiorizado pelo indivíduo, mas é exercido pelo grupo. Os participantes apresentam um alto grau de consciência em relação a essa concepção a ponto de entenderem que o compartilhamento das opiniões, das sugestões e das orientações funciona como aprendizado individual e coletivo que gera um conhecimento comum a todos.

A Criação de Competência Coletiva foi descrita como um fenômeno natural, quase que como uma consequência imediata da interação e interação dos indivíduos que buscam um objetivo comum. Os participantes ressaltam com muita frequência que essa troca ocorre mesmo na ausência de rotinas que as estimulem, as organizem ou as potencializem. As rotinas organizacionais que viessem a institucionalizar o fenômeno seriam muito bem-vindas por existir a percepção de que esta dinâmica, na maioria das vezes, é promovida pelos indivíduos e não pela organização.

Sob a perspectiva da realização das rotinas, emerge a segunda categoria que descreve o fenômeno de Compartilhar Competências nas Rotinas de Inovação como a Transformação do Fazer, considerando que no grupo de trabalho já exista um conhecimento comum acerca do problema e das incipientes ou potenciais soluções a serem desenvolvidas pelo grupo. O saber e saber-fazer coletivo construído pelo grupo é capaz de reavaliar as formas de realizar determinadas ações, práticas ou tarefas para que o grupo evolua na busca de uma solução 
diferenciada ou até mesmo inovadora. Nesta concepção, o salto da transformação do fazer acontece alicerçado por uma base de conhecimentos comuns, decorrentes do compartilhamento descrito na primeira categoria, quando o grupo criou uma competência coletiva.

As soluções inovadoras nesta segunda categoria são aquelas que mudam o resultado pela transformação do fazer. Aquilo que é acrescido ou suprimido ao processo, ao produto, ao serviço e que possibilita novas experiências, novos formatos e novas entregas, é entendido como inovação. O processo de transformar é a inovação, viabilizado pela competência coletiva do grupo.

Assim, na segunda concepção, a partir do momento em que um grupo se propõe a buscar soluções de problemas, a competência coletiva gerada pela fusão das competências individuais alavanca o potencial de um modo novo de realizar, ou seja, um modo inovador de resolver problemas.

$\mathrm{Na}$ dinâmica de trabalho vivida pelo grupo, parece que a interação de competências e a integração dos indivíduos para transformar o fazer promovem a construção, em determinados grupos, de um modelo de pensamento comum focado em buscar novas possibilidades de resolver problemas, buscar soluções inovadoras. Quando esta concepção é descrita por participantes, percebe-se que os grupos refletem coletivamente em um contexto harmônico, mas de senso crítico, pela consciência comum de que este é o caminho para chegar a uma nova solução.

Desta forma, a terceira categoria que concebe o Compartilhamento de Competências nas Rotinas de Inovação como uma Construção de Padrão de Pensamento traduz a concepção de que existe uma forma de pensar coletiva construída a partir da competência coletiva e da liberdade do grupo para transformar. Este modelo de pensar, peculiar a cada grupo, parece ser um significativo facilitador do processo de busca de soluções inovadoras de problemas.

Vale ressaltar que neste estudo, na aplicação do método fenomenográfico, a seleção dos indivíduos entrevistados utilizou a área de marketing e comunicação como o critério de escolha. Tal premissa, considerando uma disciplina (área de saber e saber-fazer) como a segmentação do campo de estudo, pode restringir a 
diversidade da amostra, além de gerar uma maior concentração nas categorias mais abrangentes. Essa observação destaca a importância do cuidado na definição do critério de seleção que utiliza a premissa de uma determinada área de atuação profissional, uma vez que o exercício da aplicação de conhecimentos específicos e as experiências de realizações das atividades de tal disciplina transitam em um universo comum aos indivíduos que compõe o campo de estudo.

O Mapa do Espaço Resultado é apresentado na Figura 1 e representa a correlação entre as categorias descritivas do estudo.

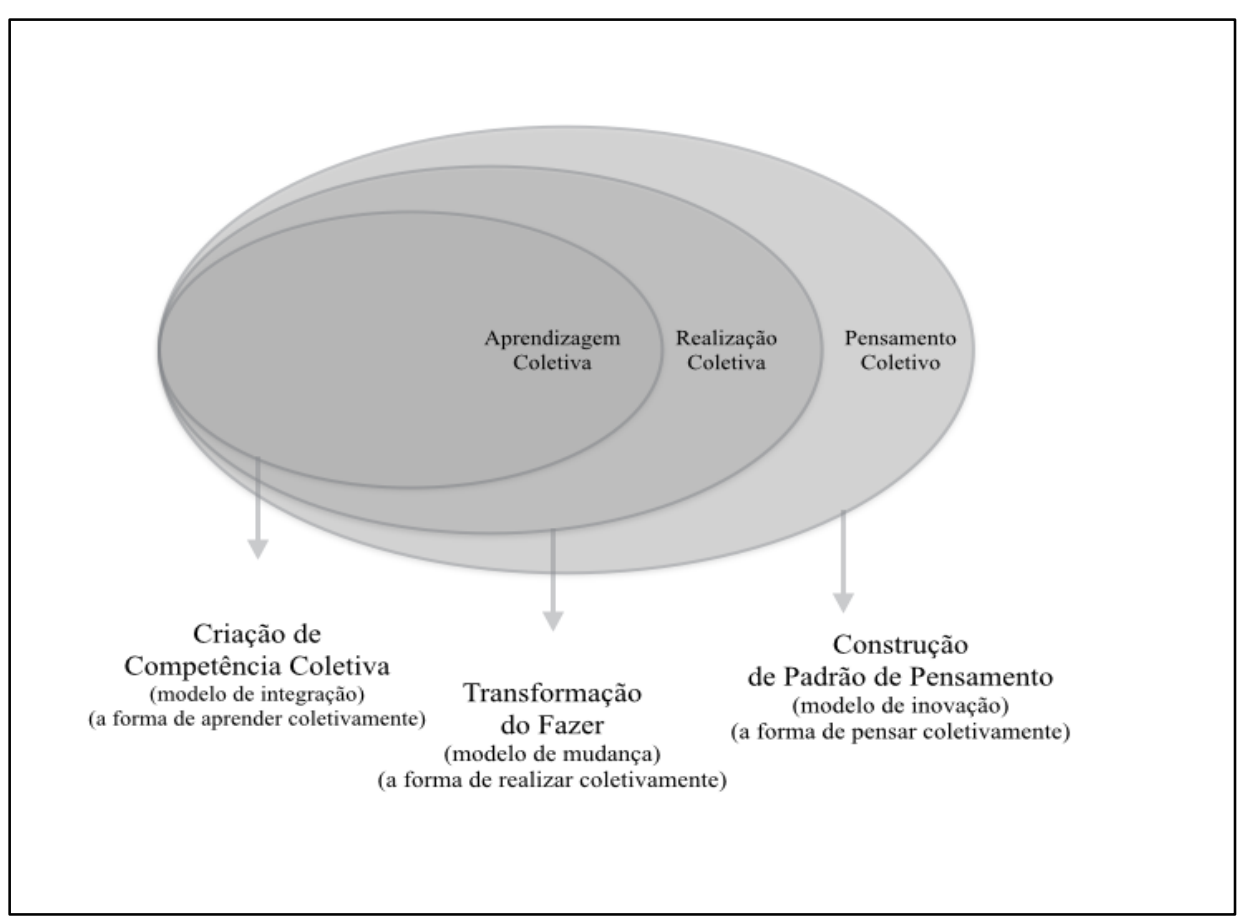

Figura 1 - Mapa do Espaço de Resultado para as concepções sobre Compartilhamento de Competências em Rotinas de Inovação.

Observando as categorias que emergiram do campo, pode-se considerar que elas respondem à pergunta de pesquisa deste estudo quanto a forma como o fenômeno de compartilhamento de competências nas rotinas de inovação. Ao longo da análise do campo, os objetivos secundários da pesquisa foram sendo respondidos: a relevância do compartilhamento e integração do conhecimento para os participantes; a percepção do estimulo que a diversidade de competências promove para que haja compartilhamento; e, quais as características individuais e coletivas que promovem com maior facilidade o fenômeno estudado.

$\mathrm{Na}$ construção do Mapa Espaço Resultado (Fig. 1), vale observar que, de acordo com a metodologia fenomenográfica quando a correlação crescente das 
concepções acerca do fenômeno é estabelecida, ela retrata a evolução da consciência do grupo quanto a importância do compartilhamento de competências para alavancar seu potencial inovador na busca de soluções de problemas. $\mathrm{Ou}$ seja, a medida que o compartilhamento de saberes (aprendizado), de saberes-fazer (realização) e de pensamentos (ideias) vão se complementando - e integrando - na dinâmica processual da busca de solução de problemas, aumentam as possibilidades do grupo em alcançar diferentes e/ou novas soluções do problema em questão.

A última categoria tenta demonstrar que, para existir um modelo de pensamento aberto às possibilidades de construção coletiva de uma solução de problema, parece ser necessário que previamente o grupo tenha construído suas competências coletiva e exercitado novas formas de fazer diferente. A partir de então, o grupo se torna uno e cria um modelo comum para elaborar ideias, navegar em possibilidades, valorar o erro e se flexibilizar para considerar tentativas coletivas visando chegar a uma nova proposta de valor. Esse exercício contínuo e orgânico, constrói uma forma de pensar do grupo, um modelo mental compartilhado pelos indivíduos, que pode se tornar um Padrão de Pensamento Coletivo.

Os níveis crescentes da consciência dos indivíduos em relação à importância dos processos integrados, faz com que as categorias apresentadas neste estudo formem uma cadeia alavancadora de dinâmicas processuais para a inovação: aprendizagem coletiva, realização coletiva e pensamento coletivo, reforçando a importância das organizações promoverem e valorizarem a criação contínua de competências coletivas e, estruturarem e formalizarem suas rotinas de inovação. 


\section{5 \\ Considerações Finais}

Este estudo buscou investigar como os indivíduos vivenciam (ou experimentam) o compartilhamento das competências individuais nas rotinas/processos de busca de solução inovadoras.

As descobertas do estudo se configuraram tão orgânicas quanto parece ser o fenômeno estudado. A ideia - em si - não recebe o mesmo destaque que o pensamento construtivo coletivo que leva até ela. $\mathrm{O}$ valor da solução, diferenciada ou inovadora, possui valor pela importância do processo que o grupo percorre até encontrá-la.

O estudo a partir dos referenciais teóricos de competências coletivas, de inovação e de rotinas organizacionais trouxe uma perspectiva ampliada para o entendimento de como os processos são experimentados nas três categorias que emergiram do estudo, que se apresentam crescentemente complementares entre si. O fluxo de Criar Competência Coletiva (primeira categoria), seguido de Transformar o Fazer (segunda categoria), levando a uma Construção de Pensamento Coletivo (terceira categoria) pode nos levar a refletir como as relações inter e multidisciplinares nas organizações deveriam ser estrategicamente estruturadas e incentivadas.

Sem dúvida, existe um vasto potencial para estudos mais aprofundados buscando entender como as rotinas organizacionais contribuem, influenciam e desencadeiam os processos de compartilhar conhecimento para busca de inovação que, ainda na maioria das empresas, se caracteriza como um processo institucionalmente incipiente.

O aprofundamento de estudos sobre o tema certamente encontrará um campo de pesquisa disponível e ávido para contribuir, uma vez que os profissionais envolvidos em atividades ligadas à estratégica, ao planejamento, ao desenvolvimento e pesquisa, dentre outras atividades, parecem ter atingido um nível de consciência avançado no que diz respeito à importância de construções coletivas para a inovação. O resultado inovador não é mais visto como uma ideia 
impactante sem alicerce em elaborações e fundamentos, mas como a imbricação de diferentes pensamentos em torno de um problema ou desafio que acontece dentro de uma dinâmica de continuidade e de crescimento orgânico dos saberes e saberes-fazer coletivos.

No caminho para aprofundar o entendimento da relação e interação entre competências coletivas e rotinas organizacionais voltadas para os processos inovadores, cabe ressaltar a importância de pesquisas futuras visando entender no contexto de aprendizados e práticas - o significado de inovação. No presente estudo fica evidente que inovação, na perspectiva de rotinas organizacionais, é percebida como um fazer - o processo - que é capaz de transformar, de mudar, de evoluir uma solução que já é conhecida ou, eventualmente, encontrar alguma proposta de valor totalmente nova.

Os grupos que constroem um Padrão de Pensamento para Inovação, como sugerido neste trabalho, percebem o valor no processo coletivo de busca de novas soluções: inovação não é o resultado alcançado, mas o caminho percorrido para chegar a uma proposta de novo valor. O resultado é inovador por ser decorrente do processo de inovar. E, inovação é uma prática coletiva.

Assim, entender melhor como as rotinas organizacionais podem contribuir para promover inovação, a partir de um saber compartilhado, seria um próximo passo para contribuir com modelos de gestão inovadores. 


\section{5 \\ Referências Bibliográficas}

ALMEIDA, P.; PHENE, A.; GRANT, R. (2008). Innovation and Knowledge Management: Scanning, Sourcing, and Integration. In: Easterby-Smith, M. Lyles, The Blackwell Handbook of Organizational Learning and Knowledge Management. Blackwell Publishing, 2008.

AWAZU, Y.; BALOH, P.; DESOUZA, K. C.; DOMBROWSKI, C.; JHA, S.; KIM, J. Y.; PAPAGARI, S. (2009). Crafting organizational innovation processes. Innovation: Management, Policy, \& Practice, 11(1) 6

BARNEY, J. (2000). Firm resources and sustained competitive advantage. JAI 17: 203-227.

BITENCOURT, C. C.; KLEIN, M. J. (2009). A dinâmica das competências coletivas entre grupos de Trabalho: o caso da parada geral de manutenção da UNIB-RS/ Braskem. São Paulo, 2009. In: XXXIII Encontro da ANPAD. Anais XXXIII Encontro ANPAD. São Paulo, 2009, 1-16.

BONINI, L. A.; SBRAGIA, R. (2011). O Modelo de Design Thinking como Indutor da Inovação nas Empresas: Um Estudo Empírico. Revista de Gestão e Projetos, 2(1), 03-25.

CHERMAN, A., PINTO, S. R. D. R. (2013). Valoração do conhecimento nas organizações: Percepções dos indivíduos e impactos nas práticas organizacionais. Tese de Doutorado. Pontifícia Universidade Católica do Rio de Janeiro, Rio de Janeiro, 2013.

CHESBROUGH, H.; TEECE, D. J. (2002). When Is Virtual Virtuous? Organizing for Innovation. Harvard Business Review, 74(1), 65-65.

CRAINER, S.; DEARLOVE, D. (2014). Inovação: como levar sua empresa para o próximo nível. 1a ed., Porto Alegre, Bookman, 2014. 180 p. 
CROSSAN, M. M.; LANE, H. W.; WHITE, R. E. (1999). An Organizational Learning Framework: From Intuition to Institution. The Academy of Management Review, 24(3), 522-537.

DAMANPOUR, F. AND SCHNEIDER, M. (2006). Phases of the Adoption of Innovation in Organizations: Effects of Environment, Organization and Top Managers. British Journal of Management, 17: 215-236.

DAMANPOUR, F. AND ARAVIND, D. (2012). Managerial Innovation: Conceptions, Processes, and Antecedents. Management and Organization Review, 8: $423-454$.

DELL'ERA, C., VERGANTI, R. (2010). Collaborative Strategies in Designintensive Industries: Knowledge Diversity and Innovation. Long Range Planning, 43(1), 123-141

FELDMAN, M. S., \& PENTLAND, B. T. (2003). Reconceptualizing organizational routines as a source of flexibility and change. Administrative Science Quarterly, 48(1), 94-118.

FIORIN, J. L. (2008). Linguagem e Interdisciplinaridade. Alea: Estudos Neolatinos, 10(1), 29-53.

GRANT, R.M. (1991) The Resource-Based Theory of Competitive Advantage: Implications for Strategy Formulation. California Management Review. 33(3) 114-135

HOEVE, A.; NIEUWENHUIS, L. (2006). Learning routines in innovation processes, Journal of Workplace Learning, 18(3), 171 - 185

HALES, M., \& TIDD, J. (2009). The practice of routines and representations in design and development. Industrial and Corporate Change, 18 (4), 551-574.

HEDBERG, B.; WOLF, R. (2001). Organizing, Learning, and Strategizing: From Construction to Discovery. In.: NONAKA, I. Handbook of Organizational Learning \& Knowledge.

JIMÉNEZ-JIMÉNEZ, D.; SANZ-VALLE, R. (2011). Innovation, organizational learning, and performance. Journal of Business Research, 64(4), 408-417. 
KODAMA, M. (2011). Knowledge Integration Dynamics: developing strategic innovation. 2a Ed., New Jersey, EUA: World Scientific \& Imperial College Press, 2011.

LE BOTERF, G. (2003). Desenvolvendo a competência dos profissionais. Porto Alegre: Bookman: Artmed.

LAKATOS, E. M.; MARCONI, M. A. Fundamentos de Metodologia Científica. 7a Ed., São Paulo: Atlas, 2010.

LAM, A. (2004). 'Organizational innovation' in J. Fagerberg, D.Mowery and R. Nelson (eds) Handbook of Innovation, Oxford University Press.

LAM, A. and Lundvall, B-A. (2007) 'The Learning organisation and national systems of competence building and innovation', in N. Lorenz and B-A Lundvall (eds) How Europe's Economies Learn: Coordinating Competing Models, Oxford University Press, pp. 110-139.

LIAO, S.; FEI, W.; LIU, C. (2008). Relationships between knowledge inertia, organizational learning and organization innovation. Technovation, 28(4), 183195.

MARTON, F. (1981) Phenomenography: Describing conceptions of the world around us. Instructional Science, 10, 177-200

MARTON, F.; BOOTH, S. A. (1997). Learning and awereness. Mahwah: Lawrence Erlbaum Inc. Publishers.

MOLON e SILVA, F. (2012). O Que Sabemos Sobre Competências Coletivas? In: Encontro Nacional de Pós-Graduação em Administração - Enanpad - R. Janeiro 2012, 15 p.

NONAKA, I.; TOYAMA, R.; BYOSIÉRE (2001). A Theory of Organizational Knowledge Creation: Understanding the Dynamic Process of Creating Knowledge. In.: NONAKA, I. Handbook of Organizational Learning \& Knowledge.

PALETZ, S. B. F.; SCHUNN, C. D.A (2010). Social-Cognitive Framework of Multidisciplinary Team Innovation. Topics in cognitive science, 2(1), 73-95. 
PARMIGIANI, A.; HOWARD-GRENVILLE, J. (2011). Routines revisited: Exploring the capabilities and practice perspective. The Academy of Management Annals, 5(1), 413-453. PAROLIN, S. R. H. (2013). Estudo multicascos sobre atividades inovativas. Revista de Administração, 48 (3), 608 - 620.

PRAHALAD, C. K., e HAMEL, G. (1990). The Core Competence of the Corporation. Harvard Business Review, 68(3), 79-91.

RETOUR, D.; PICQ, T.; DEFELIX, C.; RUAS, R. BOOKMAN (2011). Competências Coletivas: no limiar da estratégia. São Paulo: Bookman.

RUAS, R.L.; MOLON DA SILVA, F.; BECKER, G.V.; COMINI, G.M. (2013). Competências Coletivas: Resultados Teórico-Práticos Acerca De Sua Configuração Em Empresas Brasileiras. In: Encontro Nacional de Pós-Graduação em Administração - Enanpad - R. Janeiro 2013, 15 p.

RUAS, R.L.; FERNANDES B. H. R.; FERRAN J.E.M; MOLON E SILVA, F. (2010). Gestão por Competências: Revisão de Trabalhos Acadêmicos no Brasil no período 2000 a 2008. In: Encontro Nacional de Pós-Graduação em Administração - Enanpad - R. Janeiro 2010, 15 p.

SILVA, F. C. O que sabemos sobre Competências coletivas? Rio de Janeiro, 2012. In: XXXVI Encontro da ANPAD. Anais XXXVI Encontro ANPAD. Rio de Janeiro, 2012, 1-14.

SOUZA, J. C. (2013). Processo de inovação no contexto organizacional: uma análise de facilitadores e dificultadores. BBR Brazilian business review (Portuguese Ed.), 10(3), 113-136.

THAMHAIN, H. J. (2003). Managing Innovatie R\&D Teams. R\&D Management, 33(3), 297-311.

VERA, D.; CROSSAN, M. (2008). Organizational Learning and Knowledge Management: Toward an Integrative Framework. In.: The Blackwell Handbook of Organizational Learning and Knowledge Management.

ZARIFIAN, P. (2001). Objetivo competência: por uma nova lógica. São Paulo: Atlas. 


\title{
Apêndices
}

\section{Apêndice 1 \\ Roteiro Semiestruturado}

\author{
Introdução
}

A pesquisa é sobre os entendimentos e experiências que as pessoas possuem acerca do compartilhamento de competências (ou saberes) individuais nas rotinas/processos de busca de soluções inovadoras.

Durante esta entrevista farei perguntas sobre sua experiência / dia a dia profissional, e fique à vontade para abordar todos os aspectos que você considerar relevante. Meu objetivo é ouvir o que você tem a dizer sobre suas vivencias, experiências e percepções.

Nenhum entrevistado será identificado sob nenhuma perspectiva, assim como todas as informações e dados coletados serão tratados e acervados com total confidencialidade.

Nossa conversa será gravada para facilitar o registro e recuperação destes dados e informações posteriormente.

Perguntas Introdutórias

1. Iniciando, você poderia falar sobre sua idade, formação, trajetória profissional, área de atuação na empresa e tempo nesta atividade?

2. Para você, o que é competência? (citar um sinônimo)

3. Para você, o que é uma solução inovadora? 
Perguntas Centrais

1. (Experiência/vivência)

Você poderia descrever uma situação, na qual você considerou que houve compartilhamento de competências em um grupo de trabalho para se chegar a uma solução inovadora de problema? (onde, quando e em que tipo de equipe: disciplinar, multidisciplinar)

2. (Percepção)

Como você percebe que ocorre o compartilhamento das competências em trabalhos e atividades em grupos? (o processo, os fatos, etc.)

3. (Características do grupo)

Para você, quais fatores/características são importantes nas competências presentes nos grupos de trabalho que buscam soluções inovadoras?

Perguntas de Acompanhamento

4.

a. Nesta situação exemplo, que competência você exerceu/exerce?

b. Por que você considera esta situação um sinal de compartilhamento de competências na busca de soluções inovadoras?

c. No contexto de trabalho, quando esta situação ocorre?

d. No contexto de trabalho, qual o estímulo para que esta situação ocorra?

e. Como seus pares se comportam em relação a esta situação?

f. No contexto de trabalho, quando uma solução é considerada inovadora?

5.

g. Qual foi o fato que caracterizou isto (o compartilhamento de competências e a inovação)?

6.

h. A partir de que critérios / características individuais você acha que este grupo de trabalho deve ser formatado? 
Perguntas Finais

7. A partir do que conversamos, de suas colocações, percepções e experiências, que o compartilhamento de competências significa para você?

8. E, para você, qual a relação entre compartilhamento das competências de cada indivíduo do grupo (dos conhecimentos individuais) e busca de soluções inovadoras?

9. Quando coloco duas palavras: competência e conhecimento, o que você tem a dizer sobre as duas?

10. Você gostaria de acrescentar algo ao que disse anteriormente ou dizer alguma coisa sobre o assunto que não foi abordado em nossa conversa?

Finalização

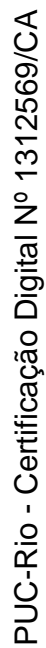

Agradecimentos. 